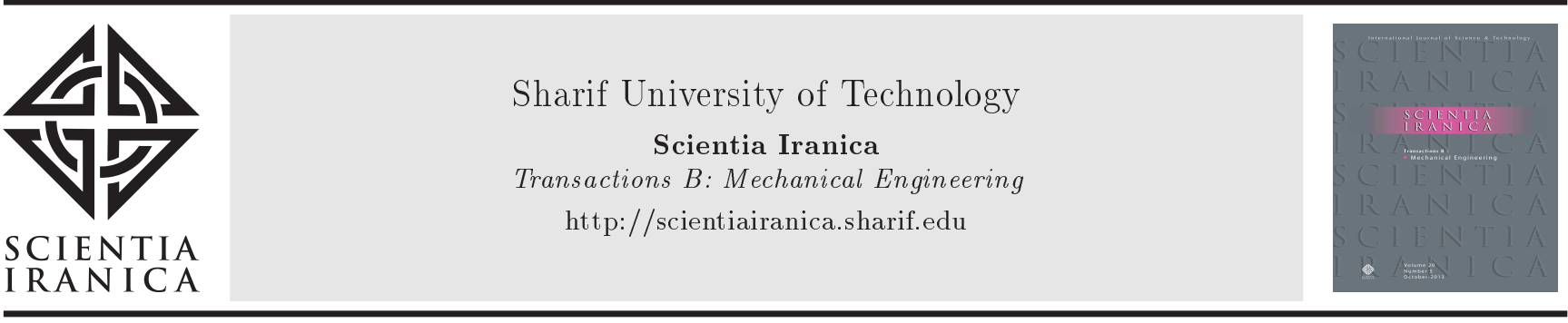

\title{
Prediction of an optimum engine response based on different input parameters on common rail direct injection diesel engine: A response surface methodology approach
}

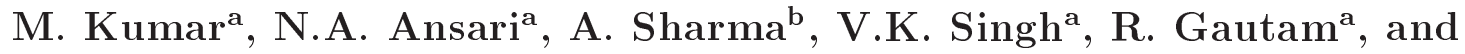 \\ Y. Singh ${ }^{\mathbf{c}, *}$ \\ a. Department of Mechanical Engineering, Delhi Technological University, Delhi, India. \\ b. Department of Mechanical Engineering, GL Bajaj Institute of Technology and Management, Greater Noida, UP, India. \\ c. Department of Mechanical Engineering, Graphic Era Deemed to be University, Dehradun, Uttarakhand, India.
}

Received 20 October 2020; received in revised form 12 January 2021; accepted 19 April 2021

KEYWORDS
Linseed;
Biodiesel;
Blend;
Performance;
Emission;
Common rail direct
injection;
Response surface
methodology.

KEYWORDS

Blend;

Performance;

Emission;

Common rail direct

Response surface

methodology.

\begin{abstract}
With increasing growth in industrialization all over the world, the need for reducing harmful pollutants gains significance, especially in the transportation sector. In this respect, the present study evaluates the effects of different engine operating parameters on the performance and emissions of a CRDI (Common Rail Direct Injection) diesel engine. The main objective of this study was to optimize the emissions as well as efficiency parameters to achieve the optimal configuration parameters for the engine using the desirability approach of Response Surface Methodology (RSM) technique, a suitable optimization approach to saving a lot of repetitive testing. It was observed that after RSM modeling, the optimized engine settings of input factors were diesel/linseed blend concentration 8.10\%, FIP (Fuel Injection Pressure) 600 bar, EGR (Exhaust Gas Recirculation) level $4.667 \%$, and load on engine $9.33 \mathrm{~kg}$. On these constant hold values, the optimized output torque, BTE (Brake Thermal Efficiency), BMEP (Brake Mean Effective Pressure), mechanical efficiency, $\mathrm{HC}$ (hydrocarbon), and $\mathrm{CO}_{2}$ carbon dioxide were calculated as $20.04 \mathrm{Nm}, 26.035 \%, 3.474 \mathrm{bar}, 52.503 \%, 28.14 \mathrm{ppmv}$, and $7.319 \%$ vol respectively. The aforementioned predicted values were experimentally validated, and the errors in the predicted values were in a limited range.
\end{abstract}

(C) 2021 Sharif University of Technology. All rights reserved.

\section{Introduction}

With a considerable shortage of the world petroleum supplies and rising consumption of petroleum products, especially transportation fuels, the need for liquid fuel replacement has gained much significance for all

\footnotetext{
*. Corresponding author.

E-mail addresses: yashvirkankara21@gmail.com (Y. Singh)
}

doi: $10.24200 /$ sci. 2021.56745 .4885 countries. Singh et al. [1] found that in the automobile industry, non-renewable diesel fuel is one of the primary fossil fuels whose burning had a detrimental effect on the atmosphere. Due to the gradual, yet rapid, depletion of fossil fuels, the search for renewable fuel sources is of importance. Gautam and Kumar [2] observed that emissions of carbon monoxide (CO), Unburnt Hydro-Carbon (UHC), carbon dioxide $\left(\mathrm{CO}_{2}\right)$, smoke particles, and oxides of nitrogen ( $\mathrm{NOx}$ ) from the Compression Ignition (CI) engines had a severe impact on human beings as well as the environment. 
Saravanan et al. [3] stated that vegetable oil could be treated as a distinctive sustainable source of biodiesel production among different alternatives due to several advantages such as readily accessible, non-toxic, nonhazardous and bio-degradable characteristics, which would be not only cost-effective but also environmentally sustainable. Karikalan et al. [4] found that biodiesel was selected as a replacement fuel that could develop the ecological situation and add to the supply of energy. Use of a biodiesel blend does not require any engine adjustment and in fewer cases, slight modifications are required to harness pure $100 \%$ biodiesel. Rajesh Kumar and Saravanan [5] observed that in diesel engines, when fuelled with vegetable oil, comparable power output and slightly lower thermal performance were detected. Furthermore, Gautam et al. [6] investigated bio-based energy fuels as a solution to energy protection, jobs, lowering the world's resources needed in consuming fossil fuels, agricultural economic growth, and utilising wasteland to produce oil-rich crops. Yongphet et al. [7] stated that biodiesel was obtained through the transesterification process in which the fatty acid (triglycerides) reacted with alcohol in the presence of a base catalyst at a specific ratio and formed alkyl fatty acid esters (biodiesel) and glycerol.

A variety of edible, non-edible oil, animal fats, etc. can be used to produce biodiesel. The present study aims to investigate linseed biodiesel. Dixit and Rehman [8] reported that linseed oil had an outstanding capacity for producing by-products as well as a strong oil standard. Linseed seeds yield $33-47 \%$ oil content under ideal conditions. Modification to the profile of fatty acids and yield improvement render linseed oil an excellent candidate to be implemented in the biodiesel industry. Of note, climatic and geographical conditions of India are efficient in linseed (Linum Usitatissimum) crop production.

With the consideration of the above factors, Ansari et al. [9] performed experiments to improve the diesel engine output and reduce pollutants such as $\mathrm{HC}$, NOx, particulates, $\mathrm{CO}$, etc.; however, $\mathrm{CO}_{2}$ was maximized using different biodiesel formulations, additives, enhancing the timing of fuel injection, higher Fuel Injection Pressure (FIP), Exhaust Gas Recirculation (EGR) techniques, pilot injection, design adjustment of the combustion system, varying CRs (Compression Ratios), etc. Maximization of $\mathrm{CO}_{2}$ is advantageous because it implies that complete fuel combustion occurs within the cylinder and $\mathrm{CO}$ molecules are mostly transformed into $\mathrm{CO}_{2}$. To some extent, each of the aforementioned approaches enjoys some benefits. Venu et al. [10] investigated the impacts of EGR on PB30 (70\% diesel $+30 \%$ palm biodiesel) dispersed with $25 \mathrm{ppm}$ $\mathrm{TiO}_{2}$ (Titanium oxide) Palm Biodiesel Nanoparticles (PBN) in the CI engine. The results of the experiment obtained for PBN-EGR were excellent compared to those of the conventional PB-EGR system, since there was a significant decline in the Brake Specific Fuel Consumption (BSFC) as well as $\mathrm{HC}$ and $\mathrm{CO}$ emissions with a rise in EGT (Exhaust Gas Temperature) over PBN. PBN-EGR NOx emissions were on a par with PB-EGR throughout the entire load. Kannan and Anand [11] found that by decreasing the FIP, the surface area of the fuel droplet would increase and the evaporation of the droplet would take a longer time to raise the $\mathrm{HC}$ and $\mathrm{CO}$ amounts. Hence, FIP had a significant impact on ignition delay and combustion characteristics. Agarwal et al. [12] conducted an experiment to evaluate the impacts of Karanja biodiesel at different FIP and injection start times. As observed, the period of fuel injection was shortened slightly with a greater biodiesel blend ratio and it declined rapidly upon increasing the FIP. With no need for hardware improvements or ECU (Electronic Control Unit) recalibration, 10\% Karanja biodiesel blends could boost the Brake Thermal Efficiency (BTE) and minimize the pollution. According to a survey conducted by several researchers, different parameters including the FIP, EGR rate, CR, IT (injection timing), engine load, and type of fuel with different concentrations could affect the performance and emission characteristics of the engines.

All of these approaches have shown some levels of benefits; however, the problems of poor efficiency and biodiesel pollution remain still unresolved. In this respect, some researchers such as Tosun et al. [13] have attempted to boost the efficiency of the biodieselfuelled engine and its blends using different optimization strategies. Many researchers have contributed to boosting the performance of an engine using biodiesel as a substitute for fossil diesel fuel through a variety of optimization techniques to minimize pollutants. For instance, Pathak et al. [14] shifted their focus to computer-based approaches since conventional approaches were so time-consuming and expensive; therefore, they could produce the same output faster and cheaper with a minimum number of trials. There are several methods generally applied to the output of an optimized engine, namely the Taguchi method, Response Surface Methodology (RSM), Artificial Neural Network (ANN), Isogeometric Analysis (IGA), Genetic Algorithm (GA), grey rational analysis, computer design methodology, and non-linear regression. Ghasemi et al. [15] stated that most of the models required a large number of experimental algorithms to develop the networks. They would also require significant computing power and a more computational period. Apart from this, RSM is a commonly used technique for solving many industrial challenges. Hamze [16] explored that RSM was a collection of mathematical and statistical approaches to simulation and problem solving, wherein many running or process variables 
affected the response. RSM becomes very efficient in the case of experiments conducted to optimize performance and minimize emissions levels.

Lingling Ma et al. [17] elaborated the key benefit of the RSM, i.e., the RSM-based studies require fewer tests and they are more time-consuming than a true experimental study. In many research reports, this technique is commonly used. A number of studies have been published on the experiments that explored the optimal blend ratios for diesel/biodiesel mixtures. Vinay and Yadav [18] optimized the parameters of efficiency and pollutants of a CI engine powered by Mahua biodiesel mixed with diesel using RSM. According to this analysis, for Mahua oil methyl esters blended with diesel, BSFC ( $\mathrm{kg} / \mathrm{kWh})$ : 0.2252, BTE (\%): 29.2885, CO (vol\%): 0.00757, HC (ppm): 5.7195, NOx (ppm): 319.78, and smoke (vol\%): 4.50 were observed in the case of optimized input parameters (40\% fuel blend and $15 \mathrm{Nm}$ load torque) as well as performance and pollution parameters for optimum solutions. Uslu and Celik [19] evaluated the impact of engine efficiency and pollution of i-Amyl Alcohol (iAA)/gasoline fuel mixture on SI engine predicted by ANN and optimized with RSM. The RSM analysis revealed that the optimum engine operating conditions included the $\mathrm{i}-\mathrm{AA}$ ratio of $15 \%$ at $8.31 \mathrm{CR}$ and $2957.58 \mathrm{rpm}$ engine speed. In this regard, an efficient method for forecasting and maximizing engine outputs with minimal testing was the ANN model with RSM support. Numerous researchers including Esonye et al. [20] have studied the strength and precision of RSM techniques in yielding the best outputs in multi-purpose data sets to maximize the emission and performance outputs of a CI engine. Molina et al. [21] studied the fuel efficiency and NOx emissions of a CI engine using response surface techniques to establish a control-oriented process. They found that approximate average BSFC and NOx errors were $2 \%$ and $6 \%$, respectively, over $5.5 \mathrm{~ms}$ duration. Krishnamoorthi et al. [22] studied the cumulative effects of CR, Injection Pressure (IP), and IT on the engine performance using all test fuels. For $\mathrm{F}(1)(80 \%$ diese $+15 \%$ bael oil $+5 \%$ diethyl ether) fuel at 230 bar IP and $18 \mathrm{CR}$ with $23^{\circ} \mathrm{bTDC}$ (before Top Dead Centre) IT, a maximum BTE of $30.05 \%$ was observed. At 230 bar IP and CR 18 with $25^{\circ} \mathrm{bTDC}$ IT, minimal $\mathrm{CO}$ of $0.41 \%$ was observed and then, NOx of $205.7 \mathrm{ppm}$ was identified at 250 bar IP and $16 \mathrm{CR}$ with $25^{\circ} \mathrm{bTDC}$ IT for $\mathrm{F}(1)$ fuel. Yatish et al. [23] employed Central Composite Design (CCD) based on the RSM model for efficient synthesis of Bauhinia Variegata oil with biodiesel. In addition, the engine output was tested for an optimized blend of biodiesel with variable engine loads during which a reduction in exhaust emissions (CO and UHC) was reported. Najafi et al. [24] employed ANN-RSM approaches to maximize biodiesel/diesel blends with energy and exergy analyses. Better engine performance was achieved with $80 \%$ engine load in the presence of $\mathrm{B} 10$ and $\mathrm{B} 20$ biodiesel blends. Parida et al. [25] experimented on CI engines and employed the RSM model to optimize the performance and emission variables by selecting engine load, CR, and fuel blend as input parameters. As observed, BSFC, BTE, HC, NOx, and CO enhanced outcomes were 0.284 $\mathrm{kg} / \mathrm{kWh}, 26.77 \%, 9.6 \mathrm{ppm}, 114.84 \mathrm{ppm}$, and 0.0059\%, respectively, with desirability 0.97 . Upon comparing the experimental results with the predicted value of RSM mode, it was revealed that the errors came below $5 \%$ except for CO. Singh et al. [26] examined the effect of different engine input factors such as engine load, timing of fuel injection, and FIP on a CI engine when powered with the blend of Pongamia biodiesel and diesel. The performance and exhaust variables were optimized using the RSM approach. Based on optimization controls, the values for optimum operational variables were calculated as $15^{\circ}$ before the peak dead centre spray time, 196.36 bar fuel spray pressure, $40 \%$ biodiesel blend, and $53 \%$ engine load. Among the checked findings and expected values, errors less than $5 \%$ were found. Therefore, they concluded that RSM with fair efficiency could optimize the factors that affect engine output. Sakthivel et al. [27] developed an RSM model for estimating the optimum input variables from waste biomass on a diesel engine fuelled by pyrolysis oil. While fuel blend ratio, CR, and engine load were considered as the input variables, BSFC, BTE, and exhaust pollutants like CO, NOx, smoke, and HC were regarded as output variables through the RSM model. They considered the optimum solution characterized by 18:1 CR, 20\% fuel blend, and 100\% load with the error ratio of less than 5\%. Veinblat et al. [28] conducted a comparative study on a CI engine to analyze the combustion properties and performance of biodiesel derived from linseed oil. It was found that linseed biodiesel had a lower NOx emission rate with maximum engine loads than soybean biodiesel. Aggrawal [29] explored the application of linseed biodiesel to CI engines in order to establish a stable engine fuel system with low-pollution properties.

Based on the above literature review, it can be stated that the engine operating variables including EGR rates, FIP, biodiesel blends, and load on the engine had a great impact on the performance and exhaust pollutants of an engine; further, these inputs parameters were optimized to obtain a specific operating configuration of an engine. This optimization was beneficial to producing maximum performance with minimum emission through RSM techniques since it could significantly reduce costs and number of trials. However, the correlation among the FIP, EGR speeds, engine load, and linseed biodiesel content in diesel and their effects on the efficiency and emissions of the 
Table 1. Thermo-physical property of different blends of linseed biodiesel.

\begin{tabular}{|c|c|c|c|c|c|c|c|}
\hline Properties & $\begin{array}{l}\text { ASTM } \\
\text { method }\end{array}$ & Diesel & LB5 & LB10 & LB15 & LB20 & $\begin{array}{c}\text { Linseed } \\
\text { methyl } \\
\text { ester }\end{array}$ \\
\hline Kinematic viscosity $\left(\mathrm{mm}^{2} / \mathrm{sec}\right) @ 40^{\circ} \mathrm{C}$ & ASTM D 445 & 2.9783 & 3.0185 & 3.0774 & 3.1058 & 3.1648 & 3.8894 \\
\hline Density $\left(\mathrm{g} / \mathrm{cm}^{3}\right)$ & ASTM 6751 & 0.830 & 0.8338 & 0.8382 & 0.8424 & 0.8461 & 0.8757 \\
\hline Calorific value $(\mathrm{kJ} / \mathrm{kg})$ & ASTM D 240 & 42100 & 41750 & 41400 & 41050 & 40600 & 39100 \\
\hline
\end{tabular}

Common Rail Direct Injection (CRDI) diesel engine through optimization techniques RSM have not been investigated yet. To this end, attempts were made to fill this gap in this study. The novelty of the current experiment lies in its application of an acceptable RSM model as a reasonable step to forecast the output and exhaust pollutants of diesel/linseed biodiesel blends and effectively find the optimal operating configuration of the CRDI diesel engine. The RSM-based desirability approach was employed in this research to refine the engine operating variables such as FIP, EGR rates, engine load, and linseed biodiesel content for the superior response of torque, BTE, Brake Mean Effective Pressure (BMEP), mechanical efficiency along with $\mathrm{CO}_{2}$, and least $\mathrm{HC}$ emissions. To evaluate the optimization through dimensionless desirability effect, Minitab'17 software was employed.

\section{Material and methodology}

\subsection{Production of linseed biodiesel}

The present study was carried out on a CRDI diesel engine fuelled with linseed biodiesel blended with neat diesel oil. The linseed biodiesel was made of raw linseed oil bought from a nearby New Delhi vendor. Later, it was converted into linseed biodiesel (linseed methyl ester) through the transesterification process. In this process, $100 \mathrm{ml}$ of linseed oil with Free Fatty Acid (FFA) less than $2 \%$ was taken into a beaker and heated to $110^{\circ} \mathrm{C}$ to eliminate water content, as illustrated in Figure 1. First, the oil was allowed to cool to approximately $60^{\circ} \mathrm{C}$; then, a mixture of methanol (20 $\mathrm{ml}$ ) and $\mathrm{KOH}$ (potassium hydroxide) (1 gram) was added slowly to the oil which was constantly stirred for around 30-40 minutes. The beaker was then covered with hard cardboard. Next, it was cooled down in a separating funnel for about 24 hours without any agitation. The mixture was formed into two layers as a result of gravity effect. The heavy component, i.e., glycerol, was settled down, and the upper element was fatty acid ester, i.e., linseed biodiesel. 'Water washing' on methyl ester was performed to eliminate the impurities of glycerol and $\mathrm{KOH}$, and pure linseed biodiesel was obtained from heating the mixture at $110^{\circ} \mathrm{C}$ for almost 20 minutes to remove any water and methanol evidence. Dixit and Rahman [8] found

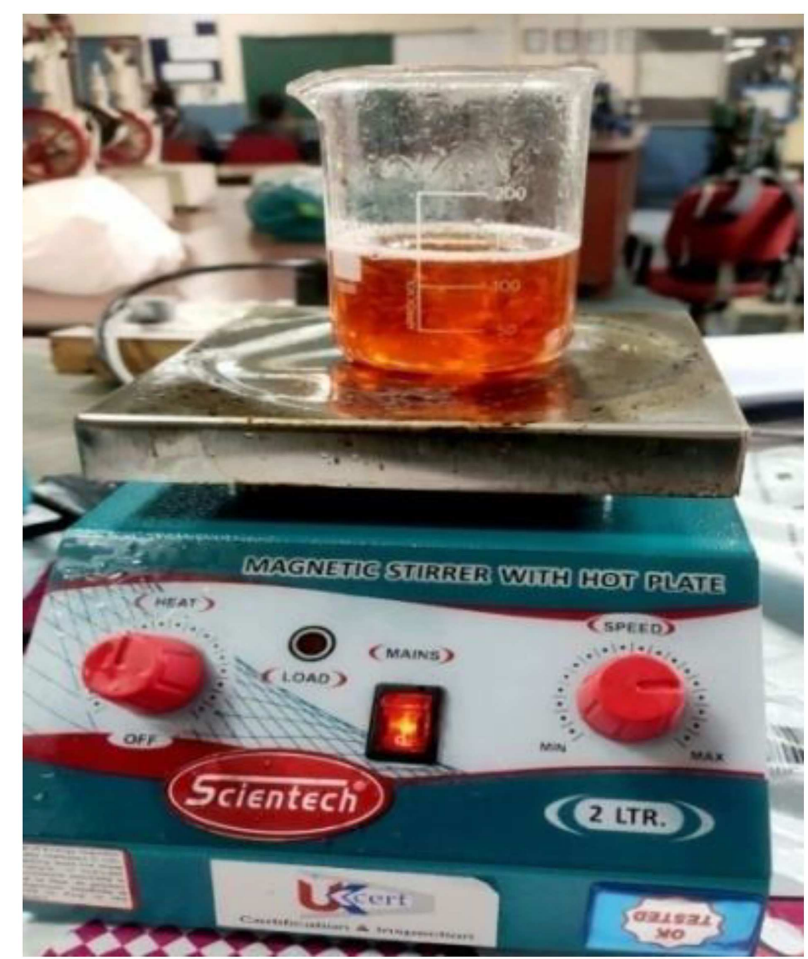

Figure 1. The transesterification process.

that the process of transesterification played a role in reducing the viscosity of oil, thus making it suitable for application in a diesel engine. Here, $5 \%, 10 \%, 15 \%$, and $20 \%$ of linseed biodiesel were mixed with neat diesel (\% age by volume) and marked as LB5, LB10, LB15, and LB20 for testing in the en gine. The thermophysical properties of the blend of linseed biodiesel are shown in Table 1.

\subsection{Experimental setup and procedure}

The engine used to test the blending fuel is a singlecylinder CRDI VCR (Variable Compression Ratio) diesel engine with four strokes running at a constant speed of $1500 \mathrm{rpm}$. The engine was attached to an eddy current dynamometer with a water-cooling mechanism to evaluate the engine load, as shown in Figure 2. Table 2 displays the technical specification of the engine test setup. The engine was adjusted at $23^{\circ}$ bTDC fuel IT (recommended by the manufacturer) and $\mathrm{C}$ of $18: 1$. Five selected research fuels were prepared for this study namely neat diesel, LB5, LB10, LB15, and LB20. The 
Table 2. The technical specification of the CRDI VCR (Common Rail Direct Injection Variable Compression Ratio) engine.

\begin{tabular}{ll}
\hline \multicolumn{1}{c}{ Make } & \multicolumn{1}{c}{ KIRLOSKAR } \\
\hline Product & (computerized) CRDI VCR Engine test setup 244 \\
Engine & 4-stroke, single cylinder, stroke $110 \mathrm{~mm}, 661 \mathrm{cc}$, bore $87.5 \mathrm{~mm}$, \\
& water-cooled. Power 3.5 KW @ $1500 \mathrm{rpm}$, range of CR 12-18:1. \\
Connecting rod length & $234 \mathrm{~mm}$ \\
Dynamometer & Eddy current, water-cooled type with loading unit \\
Injector & Type solenoid driven \\
EGR & Water cooled, range 0-15\% \\
Piezo sensor & Combustion: Range 350 Bar with low noise cable \\
Load indicator & Digital, range 0-50 kg, supply 230 VAC \\
Load sensor & Load cell, type strain gauge, range 0-50 kg \\
Fuel flow transmitter & DP transmitter, range 0-500 mm WC \\
Temperature sensor & Thermocouple, type K \\
Software & "Engine soft" Engine performance analysis software \\
Rota-meter & Engine cooling 40-400 LPH; Calorimeter 25-250 LBH \\
\hline
\end{tabular}

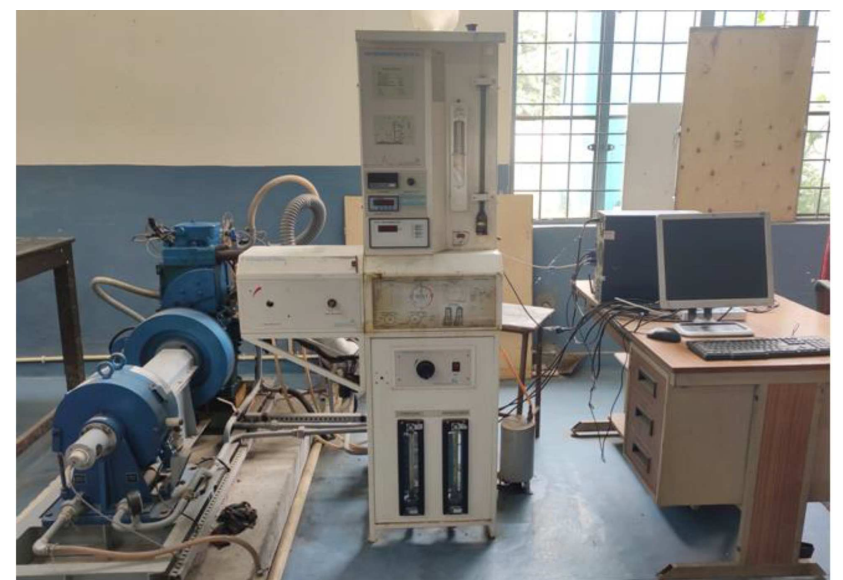

Figure 2. The Common Rail Direct Injection (CRDI) diesel engine setup [30].

performance parameters such as BTE, BMEP, torques, and mechanical efficiency were measured in the VCR engine using lab view oriented software "EngineSoft" attached to the engine. Emission variables such as $\mathrm{CO}_{2}$ and $\mathrm{HC}$ were analyzed using an AVL gas analyzer. The specifications, accuracy, and resolution of an AVL Gas Analyzer "AVL DIX 650" are shown in Table 3.

The tests were carried out in different settings for the engine using five specific FIP (500, 525, 550, 575 , and 600 bar) with five distinct EGR levels $(0 \%$, $3.5 \%, 7 \%, 10.5 \%$, and $14 \%$ ), engine loads (0 kg, $3 \mathrm{~kg}$, $6 \mathrm{~kg}, 9 \mathrm{~kg}$, and $12 \mathrm{~kg}$ ), and linseed biodiesel/diesel blends $(0 \%, 5 \%, 10 \%, 15 \%$, and $20 \%)$. The magnitude of EGR varied progressively upon raising the EGR valve and keeping the records. The cold EGR method was used for this analysis. Saravanan [31] noted that the cold EGR technique decreased the intake charge and maximized in-cylinder temperature which was a favorable condition for the formation of $\mathrm{NOx}$ pollutants. The re-circulated flue gas temperature must be held colder than that of the exhaust engine and warmer than that of the intake air charge.

Each test was executed three times and their mean was considered in the analysis. In addition, $\mathrm{HC}$ and $\mathrm{CO}_{2}$ emissions were measured in tests, and the readings were counted for torque, BTE, BMEP, and mechanical efficiency.

\subsubsection{Uncertainty analysis}

Samaniego et al. [32] stated that because of such variables as testing, operator observation, operating environments, and environmental conditions, experimental studies would be more likely to run into many defects and uncertainties. The tests were conducted under similar operation conditions, such as engine temperature and environmental conditions (ambient temperature of $26 \pm 4^{\circ} \mathrm{C}$ and relative humidity of $62 \pm 2 \%$ ), for all fuels to improve the confidence level of the tests.

To prove the validity of the experiments, uncertainty analysis is required. The outcome is determined from the key measurements in every experiment. The percentage uncertainties in different variables such as torque, BTE, BMEP, and mechanical efficiency were determined using the percentage uncertainties of different methods used in the experiment. The uncertainties of the different methods used are listed in Table 4.

\subsection{Response Surface Methodology (RSM)}

RSM is a collection of mathematical methods that can be used for modeling and evaluating problems 
Table 3. The technical specification of AVL gas analyzer.

\begin{tabular}{|c|c|}
\hline Parameters & Specification \\
\hline Type & AVL DIX 650 \\
\hline Operating temperature & $5 \ldots 40^{\circ} \mathrm{C}$ \\
\hline Warm up time & Approx... 2 min \\
\hline Dimension & W $344 \times$ D $252 \times$ H 85 \\
\hline Interface & USB, Bluetooth Class 1, RS 232 (AK protokoll) \\
\hline Voltage supply & Via AVL DITEST CDS Basic Unit: 11.25 V DC \\
\hline Measurement range & $\mathrm{CO}_{2}=0 \ldots 20 \%$ vol $\mathrm{HC}=0 \ldots 30.000 \mathrm{ppm}$ vol \\
\hline Resolution & $\mathrm{CO}_{2}=0.01 \%$ vol $\mathrm{HC}=<2.000: 1 \mathrm{ppm}$ vol \\
\hline Accuracy & $\begin{aligned} \mathrm{CO}_{2}= & <16.0 \% \text { vol: } \pm 0,3 \% \text { vol, } \pm 3 \% \text { o.M. } \\
& \leq 16.0 \% \text { vol: } \pm 5 \% \text { o.M. } \\
\mathrm{HC}= & <2000 \text { ppm vol: } \pm 4 \text { ppm vol: } \pm 3 \% \text { o.M. } \\
& \geq 5000 \text { ppm vol: } \pm 5 \% \text { o.M. } \\
& \geq 10000 \text { ppm vol: } \pm 10 \% \text { o.M }\end{aligned}$ \\
\hline
\end{tabular}

Table 4. Uncertainty associated with parameters.

\begin{tabular}{ccccc}
\hline $\begin{array}{c}\text { Measuring } \\
\text { quantity }\end{array}$ & Instrument & $\begin{array}{c}\text { Manufacturer } \\
\text { (model) }\end{array}$ & Range & Uncertainty \\
\hline $\mathrm{CO}_{2}$ emission & Gas analyzer & AVL DIX 650 & $0-20 \%$ vol & $\pm 5 \%$ \\
$\mathrm{HC}$ emission & Gas analyzer & AVL DIX 650 & $0-30.000 \mathrm{ppm}$ vol & $\pm 5 \%$ \\
\hline
\end{tabular}

where multiple variables affect the response of interest with the objective of maximizing it. In practice, the necessity of the response surface is felt in the case of the sample point to be chosen such that with a small number of experiments, a reasonably reliable model can be produced. These fitting points can be selected through experimental designs. A complete factorial modeling methodology was also used to conduct the test matrix of the present inquiry. The experimental effects of the response variables derived from the maximum factorial design matrix were used to shape the quadratic response surface models. Relationships were formulated using the least square method. In RSM, the correlation between the response variable $y$ and the parameters $x_{1}, x_{2}, x_{3}, \cdots, x_{n}$ is commonly represented as follows:

$$
Y=f\left(x_{1}, x_{2}, x_{3}, x_{4}, \ldots, x_{n}\right)+\varepsilon
$$

where $x_{1}, x_{2}, x_{3}, x_{4}, \cdots, x_{n}$ are the input variables of the engine, $y$ is the engine output needed for boosting it, $\varepsilon$ the error or noise found in response $y$, and $f$ the response surface.

In Eq. (1), the function $f$ corresponds to the correlation between a response variable and a factor which is normally unknown. Hence, in RSM, the initial step is to find an adequate approximation between the unknown factors and response variable. The linear model is the simplest approximation function (linear model) used for representing the relationship between a response variable and unknown factors, as illustrated in the following:

$$
Y=\beta_{0}+\sum_{i=1}^{k} \beta_{i} x_{i} \sum_{i=1}^{k} \beta_{i i} x_{i}^{2}+\sum_{j \leq 1}^{k} \beta_{i j} x_{i} x_{j}+\varepsilon,
$$

where $Y$ is the response, $x_{i}$ is the magnitude of the factors, $\beta_{0}, \beta_{i}, \beta_{i i}$, and $\beta_{i j}$ are the coefficients of regression, $i$ and $j$ are the linear and quadratic coefficients, and $\varepsilon$ is the experimental error. Eq. (2) can be assumed to be the extension of a Taylor expansion (of degree 2) of any real underlying function.

In this model of RSM, the linseed biodiesel concentrations in the blend, FIP, EGR, and load are considered as the input variables that can potentially affect the output response such as torque, BTE, BMEP, mechanical efficiency, $\mathrm{HC}$, and $\mathrm{CO}_{2}$. The input parameters are design variables and their limiting range includes the design constraints. The levels of different in put factors are shown in Table 5 . Here, the mid-value is assumed to be 0 for input variables. The assigned Rotatable Central Composite Design (RCCD) values are $-2,-1,0,1$, and 2 .

The main objective of using RSM techniques here is to reach the proximity of the optimum quickly and effectively. The simplest version of the model was 
Table 5. Input parameters with their levels.

\begin{tabular}{ccccc}
\hline Coded levels & Blend (\%) & FIP (bar) & EGR (\%) & Load (kg) \\
\hline-2 & Diesel & 500 & 0 & 0 \\
-1 & LB5 & 525 & 3.5 & 3 \\
0 & LB10 & 550 & 7 & 6 \\
1 & LB15 & 575 & 10.5 & 9 \\
2 & LB20 & 600 & 14 & 12 \\
\hline
\end{tabular}

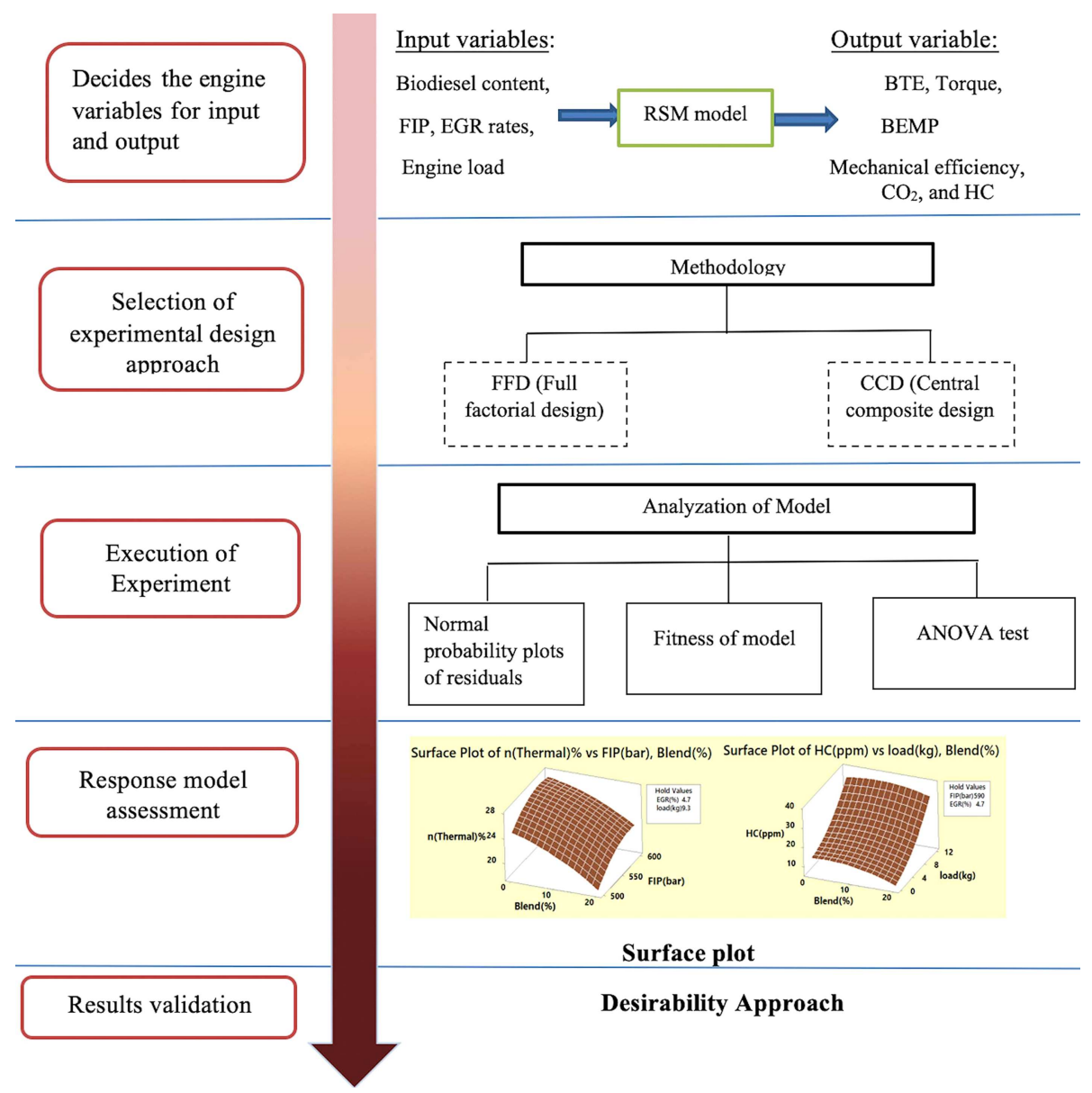

Figure 3. Flowchart for the Response Surface Methodology (RSM) approach.

then used, i.e., the linear model. The association between variables was also considered negligible and only primary impacts were taken into account. The flowchart for the RSM approach is shown in Figure 3.

\subsection{RSM modeling}

A combination of control factors leading to the ideal solution was taken into account in the study of engine performance. To assess the value for each parameter within the defined range, the variance factors were studied and applied to different parameters of the inputs. These results were developed based on the linear regression model driven by the software. The tests were conducted on different combinations of factors based on the design matrix run order, as observed in Table 6, and the corresponding response values were recorded. This process includes a minimum of 31 tests with multiple input parameter combinations. Optimization was achieved using RSM's desirability by Derringer of which the optimum solution was considered to be the one with the highest desirability. The resulting combination of variables for the optimal solution is known as the right variable for the operation of the engine. Analysis of Variance (ANOVA) generates empirical information with regard to the future benefits.

A total of 31 runs of $2^{p}$ factorial runs, $2 p$ axial runs, and 7 centre point runs consist of the control variables as well as the numerical and coded values 
Table 6. Experimental design matrix.

\begin{tabular}{|c|c|c|c|c|c|c|c|c|c|c|}
\hline Exp. no. & $\begin{array}{c}\text { (Linseed) } \\
\text { Blend } \\
(\%)\end{array}$ & $\begin{array}{l}\text { FIP } \\
\text { (bar) }\end{array}$ & $\begin{array}{c}\text { EGR } \\
(\%)\end{array}$ & $\begin{array}{c}\text { Load } \\
(\mathrm{kg})\end{array}$ & $\begin{array}{c}\text { Torque } \\
(\mathrm{Nm})\end{array}$ & $\begin{array}{c}\text { BTE } \\
(\%)\end{array}$ & $\begin{array}{c}\boldsymbol{\eta} \\
(\mathrm{Mech}) \\
(\%)\end{array}$ & $\begin{array}{c}\text { BMEP } \\
\text { (bar) }\end{array}$ & $\begin{array}{c}\text { HC } \\
(\text { ppmv) }\end{array}$ & $\begin{array}{c}\mathrm{CO}_{2} \\
(\% \text { vol })\end{array}$ \\
\hline 1 & 15 & 575 & 10.5 & 9 & 16.19 & 22.37 & 50.406 & 3.068 & 29 & 6 \\
\hline 2 & 10 & 550 & 7 & 6 & 11.29 & 21.41 & 41.688 & 2.139 & 23 & 4.2 \\
\hline 3 & 10 & 550 & 7 & 6 & 11.29 & 21.41 & 41.688 & 2.139 & 23 & 4.2 \\
\hline 4 & 10 & 550 & 14 & 6 & 9.49 & 20.41 & 37.247 & 1.799 & 29 & 3.7 \\
\hline 5 & 15 & 525 & 10.5 & 3 & 2.62 & 9.06 & 14.451 & 0.497 & 20 & 2.8 \\
\hline 6 & 5 & 525 & 10.5 & 3 & 4.33 & 9.43 & 21.718 & 0.820 & 25 & 2.85 \\
\hline 7 & 15 & 575 & 10.5 & 3 & 4.77 & 11.26 & 23.472 & 0.903 & 16 & 2.6 \\
\hline 8 & 5 & 525 & 3.5 & 9 & 17.55 & 23.53 & 52.206 & 3.326 & 35 & 7.05 \\
\hline 9 & 5 & 525 & 10.5 & 3 & 4.33 & 9.43 & 29.851 & 0.820 & 25 & 3.05 \\
\hline 10 & 10 & 550 & 7 & 0 & 0.127 & 0.4 & 0.808 & 0.024 & 13 & 1.5 \\
\hline 11 & 10 & 550 & 7 & 6 & 11.29 & 21.41 & 41.688 & 2.139 & 23 & 4.2 \\
\hline 12 & 10 & 550 & 0 & 6 & 12.69 & 21.91 & 44.457 & 2.404 & 20 & 4.8 \\
\hline 13 & 5 & 575 & 3.5 & 9 & 19.7 & 25.73 & 55.044 & 3.372 & 31 & 6.85 \\
\hline 14 & 10 & 550 & 7 & 6 & 11.29 & 21.41 & 41.688 & 2.139 & 23 & 4.2 \\
\hline 15 & 10 & 550 & 7 & 12 & 21.92 & 26.1 & 57.450 & 4.153 & 41 & 7.8 \\
\hline 16 & 15 & 575 & 3.5 & 3 & 6.57 & 12.18 & 29.596 & 1.245 & 13 & 3.2 \\
\hline 17 & 5 & 575 & 10.5 & 9 & 17.9 & 24.64 & 52.802 & 3.392 & 25 & 6.25 \\
\hline 18 & 0 & 550 & 7 & 6 & 12.79 & 24.9 & 63.007 & 2.424 & 24 & 4.4 \\
\hline 19 & 5 & 575 & 10.5 & 3 & 6.48 & 11.63 & 31.144 & 1.304 & 21 & 2.85 \\
\hline 20 & 10 & 500 & 7 & 6 & 9.89 & 20.51 & 38.532 & 1.875 & 28 & 4.9 \\
\hline 21 & 10 & 600 & 7 & 6 & 12.79 & 23.31 & 44.615 & 2.423 & 20 & 4.7 \\
\hline 22 & 5 & 525 & 10.5 & 9 & 15.75 & 22.44 & 49.629 & 2.984 & 38 & 6 \\
\hline 23 & 10 & 550 & 7 & 6 & 11.29 & 21.41 & 41.688 & 2.139 & 23 & 4.2 \\
\hline 24 & 10 & 550 & 7 & 6 & 11.29 & 21.41 & 41.688 & 2.139 & 23 & 4.2 \\
\hline 25 & 15 & 525 & 3.5 & 9 & 15.84 & 21.06 & 49.750 & 3.001 & 30 & 6.35 \\
\hline 26 & 15 & 575 & 3.5 & 9 & 17.99 & 23.23 & 52.911 & 3.409 & 26 & 6.6 \\
\hline 27 & 15 & 525 & 10.5 & 9 & 15.84 & 20.17 & 52.880 & 3.001 & 30 & 6.2 \\
\hline 28 & 5 & 575 & 3.5 & 3 & 8.28 & 12.64 & 34.537 & 1.569 & 18 & 3.45 \\
\hline 29 & 10 & 550 & 7 & 6 & 11.29 & 21.41 & 41.688 & 2.139 & 23 & 4.2 \\
\hline 30 & 15 & 525 & 3.5 & 3 & 4.42 & 9.98 & 22.062 & 0.838 & 17 & 3.4 \\
\hline 31 & 20 & 550 & 7 & 6 & 10.19 & 19.85 & 43.827 & 1.931 & 16 & 4 \\
\hline
\end{tabular}

used in the RCCD matrix. In the present case, all four control factors ( $p$ ) were taken into consideration.

Therefore, the total number of trails is equal to: $2^{p}+2 p+7=2^{4}+(2 * 4)+7=31$.

\subsubsection{Sensitivity Analysis (SA)}

$\mathrm{Vu}-\mathrm{Bac}$ et al. [33] stated that the model became more intricate due to the increasing computation power. In general, the more complex the models are because of randomness in the input parameters, the greater the variability of the model outputs. The variance in input parameters, as well as the calibration and evaluation of the mathematical models, must determine the extent of change in the model output. These are the reasons why Sensitivity Analysis (SA) is a great aid. In this regard, in many disciplines, such as material simulation and structural architecture, ambiguity and sensitivity analyses have recently caught widespread attention.

The purpose of using RSM as a method for SA was to enhance the analyst's understanding of the sensitivity between the model output (response) and its relevant input variables and then, to employ this data to enhance the decision model. Bauer Jr. et al. [34] discovered how the application of RSM for SA to a decision analysis enjoyed two main advantages. First, a major reduction was observed in the overall 
number of cycles of effect diagram solution (decision tree) required for a detailed study of sensitivity. This reduction is considered as the complexity of the model grows. Second, additional knowledge was acquired from RSM open to policymakers. These insights can be obtained from calculating the basic coefficients (effects) of significant variables and defining the relationship among the variables. These insights are invisible to approaches to one-way sensitivity research.

RSM is widely used in computer modeling to carry out SA. Typically, simulation models have multiple input variables, only a fraction of which is typically important in the modeling area.

\subsection{RSM modeling results}

The ANOVA results of torque, BTE, mechanical efficiency, BMEP, $\mathrm{HC}$, and $\mathrm{CO}_{2}$ are shown in Tables 7 and 8. According to the results from ANOVA, the $p$-value is considered the most important factor. Awad et al. [35] stated that the $p$-value for different parameters must not be more than 0.05 , and the parameters with a $p$ value greater than 0.05 are considered as insignificant. The variables with $p$-values less than 0.05 are indicative of the great impact of these variables on the developed model. According to Table 7, in the case of BTE, the $p$ - values of blend content, FIP, and EGR are greater than 0.05 , and that of the engine load is less than 0.05 for the load. Here, the load on the engine has a significant impact on the efficiency of the engine. Similarly, for torque, the $p$-value for all parameters is less than 0.05 . For mechanical efficiency, the $p$-values of FIP and EGR are higher than 0.05; however, those of load and blend content are less than 0.05 , thus pointing to the great impact of the load and blend \% on the mechanical efficiency. The $p$-value for all parameters for BMEP and $\mathrm{HC}$ emissions is less than 0.05, as observed in Table 8. According to this table, all input parameters can significantly affect BMEP and $\mathrm{HC}$ emissions. For $\mathrm{CO}_{2}$ emissions, the $p$-values of the blend ratio and FIP are more than 0.05 and those of the load and EGR are less than 0.05, indicating that the EGR and engine load have a more considerable effect on $\mathrm{CO}_{2}$ emission.

The models have also been tested using a computational approach and decision coefficient $R^{2}$. According to Saríkaya, and Güllü [36], $R^{2}$ values less than 1 illustrated that the experimental effects were consistent with the findings of the model, indicating that the reliability was very strong as can be seen Table 9. It was found that $R^{2}$ values are $99.57 \%$, $80.85 \%, 84.97 \%, 96.54 \%, 88.57 \%$, and $96.58 \%$ for

Table 7. Analysis of Variance (ANOVA) results for torque, Brake Thermal Efficiency (BTE), and mechanical efficiency.

\begin{tabular}{|c|c|c|c|c|c|c|c|c|c|c|c|c|c|}
\hline \multirow{2}{*}{ Sources } & \multirow{2}{*}{ DF } & \multicolumn{4}{|c|}{ Torque } & \multicolumn{4}{|c|}{ BTE } & \multicolumn{4}{|c|}{ Mechanical efficiency } \\
\hline & & Adj. SS & Adj. MS & $F$-value & $P$-value & Adj. SS & Adj. MS & $F$-value & $P$-value & Adj. SS & Adj. MS & $F$-value & $P$-value \\
\hline Regression & 4 & 846.635 & 211.659 & 1495.60 & 0.000 & 976.08 & 244.021 & 27.44 & 0.000 & 4693.40 & 1173.35 & 36.74 & 0.000 \\
\hline Blend $(\%)$ & 1 & 11.797 & 11.797 & 83.36 & 0.000 & 19.25 & 19.254 & 2.17 & 0.153 & 221.22 & 221.22 & 6.93 & 0.014 \\
\hline FIP (bar) & 1 & 18.936 & 18.936 & 133.80 & 0.000 & 21.63 & 21.633 & 2.43 & 0.131 & 88.19 & 88.19 & 2.76 & 0.109 \\
\hline $\operatorname{EGR}(\%)$ & 1 & 15.073 & 15.073 & 106.51 & 0.000 & 10.07 & 10.074 & 1.13 & 0.297 & 66.04 & 66.04 & 2.07 & 0.162 \\
\hline Load $(\mathrm{kg})$ & 1 & 775.822 & 775.822 & 5482.04 & 0.000 & 901.89 & 901.886 & 101.42 & 0.000 & 4202.62 & 4202.62 & 131.58 & 0.000 \\
\hline Lack-of-fit & 19 & 3.680 & 0.194 & $*$ & $*$ & 23.21 & 12.169 & $*$ & * & 797.35 & 41.97 & 8.88 & 0.003 \\
\hline
\end{tabular}

Table 8. Analysis of Variance (ANOVA) results for Brake Mean Effective Pressure (BMEP), HC, and $\mathrm{CO}_{2}$.

\begin{tabular}{|c|c|c|c|c|c|c|c|c|c|c|c|c|c|}
\hline \multirow{2}{*}{ Sources } & \multirow{2}{*}{ DF } & \multicolumn{4}{|c|}{ BMEP } & \multicolumn{4}{|c|}{$\mathrm{HC}$} & \multicolumn{4}{|c|}{$\mathrm{CO}_{2}$} \\
\hline & & Adj. SS & Adj. MS & $F$-value & $P$-value & Adj. SS & Adj. MS & $F$-value & $P$-value & Adj. SS & Adj. MS & $F$-value & $P$-value \\
\hline Regression & 4 & 28.8027 & 7.4507 & 181.49 & 0.000 & 1170.82 & 292.705 & 51.91 & 0.000 & 67.6269 & 16.9067 & 183.41 & 0.000 \\
\hline Blend (\%) & 1 & 0.9670 & 0.9670 & 23.56 & 0.000 & 104.70 & 104.704 & 18.57 & 0.000 & 0.2696 & 0.2696 & 2.93 & 0.099 \\
\hline FIP (bar) & 1 & 0.5922 & 0.5922 & 14.42 & 0.001 & 122.02 & 122.017 & 21.64 & 0.000 & 0.0301 & 0.0301 & 0.33 & 0.573 \\
\hline $\operatorname{EGR}(\%)$ & 1 & 0.4834 & 0.4824 & 11.78 & 0.002 & 42.36 & 42.362 & 7.51 & 0.011 & 1.7860 & 1.7860 & 19.38 & 0.000 \\
\hline Load (kg) & 1 & 26.9597 & 26.9597 & 656.70 & 0.000 & 902.44 & 902.444 & 160.05 & 0.000 & 63.4019 & 63.4019 & 687.80 & 0.000 \\
\hline Lack-of-fit & 19 & 1.0674 & 0.0562 & $*$ & $*$ & 146.60 & 7.716 & $*$ & $*$ & 2.3767 & 0.1251 & 43.78 & 0.000 \\
\hline
\end{tabular}

Table 9. Assessment of the model.

\begin{tabular}{lcccc}
\hline Model & $\mathbf{S}$ & $\mathbf{R}^{\mathbf{2}} \mathbf{( \% )}$ & Reg. $\mathbf{R}^{\mathbf{2}(\boldsymbol{\%})}$ & Pred. $\left.\mathbf{R}^{\mathbf{2}} \mathbf{\%}\right)$ \\
\hline Torques & 0.376192 & 99.57 & 99.50 & 99.32 \\
BTE & 2.98206 & 80.85 & 77.90 & 72.35 \\
$\eta$ (Mech.) & 5.65152 & 84.97 & 82.65 & 76.68 \\
BMEP & 0.202615 & 96.54 & 96.01 & 94.61 \\
$\mathrm{HC}$ & 2.37453 & 88.87 & 87.16 & 82.95 \\
$\mathrm{CO}_{2}$ & 0.303612 & 96.58 & 96.05 & 95.26 \\
\hline
\end{tabular}




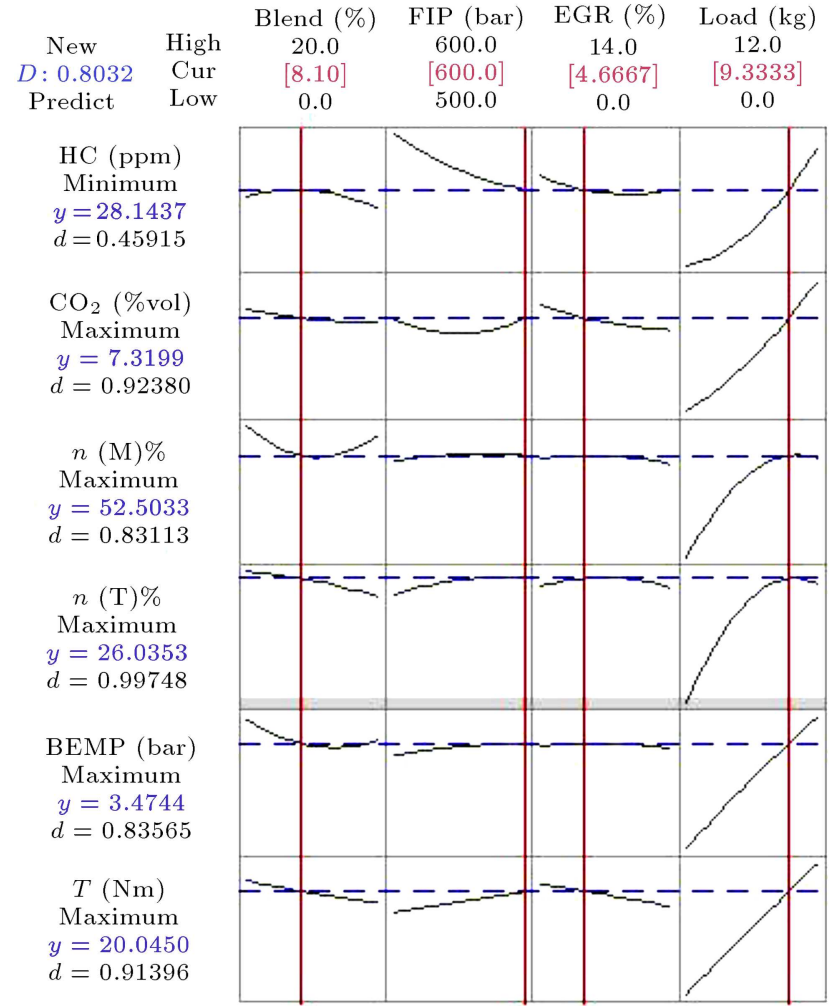

Figure 4. The Response Surface Methodology (RSM) optimizer.

torque, BTE, mechanical efficiency, BMEP, HC, and $\mathrm{CO}_{2}$, respectively. These $R^{2}$ values are nearly close to 1 and this model yields reliable results.

\subsection{Optimization response}

In the present analysis, the RSM optimizer was employed to boost the operating characteristics of the engine. The RSM optimizer is a method for configuring multi-targets such as IC engine cases. The maximum values of BMEP, BTE, torque, and mechanical efficiency along with $\mathrm{CO}_{2}$ as well as the least value of $\mathrm{HC}$ were taken as objectives from an array of the tested conditions.

The optimum values for BMEP, BTE, torque, mechanical efficiency, $\mathrm{HC}$, and $\mathrm{CO}_{2}$ were calculated as 3.576 bar, $26.64 \%, 20.04 \mathrm{Nm}, 54.343 \%, 28.71 \mathrm{ppmv}$, and $7.117 \%$ vol, respectively, with the respective optimum engine operating variables at $8.10 \%$ linseed blend ratio with diesel, FIP 600 bar, EGR 4.667\%, and engine load $9.33 \mathrm{~kg}$, as listed in Figure 4. The desirability approach to this optimization was obtained as 0.8032 . In addition, RSM was employed to estimate and modify the engine output parameters for variables within the test value series because it reduced the research burden substantially, thus saving time and costs.

\section{Results and discussion}

In this section, the effects of four CRDI diesel engine input factors on five engine output responses (BTE, mechanical efficiency, BMEP, torque, $\mathrm{HC}$, and $\mathrm{CO}_{2}$ ) are elaborated. All these four engine input factors (the blend ratio, FIP, EGR rates, and engine load) cannot vary simultaneously during surface plotting.

Therefore, in this experiment, a MINITAB 17 program was employed to produce a surface plot between two engine controls, while two other engine control variables, known as hold values, remained unchanged. These hold values are the central values of the RCCD table described on the upper right corner of each surface plot.

\subsection{Impact of control factors on BTE $\eta$ (thermal)}

This section evaluates the impact of several parameters like FIP, EGR rates, blend ratio, and engine load on the BTE, as shown in Figure 5. The surface plot in Figure 5(a) shows the effect of BTE with blend ratio and EGR\% when the hold values are (FIP, engine load) constant (590 bar and $9.3 \mathrm{~kg}$ ). According to the response surface plot, upon increasing the concentration of linseed biodiesel in the blend, the output of the engine would subsequently decrease. Hence, the values of BTE of LB20 were found to be the least and diesel had the maximum value among all test fuels. This could be attributed to the high viscosity and low Calorific Value (CV) of linseed biodiesel relative to neat diesel, thus resulting in poor atomization and improper combustion of fuel. In addition, a boost to BSFC could be another reason for it since its associated density is always reduced by increasing the blend content. Introduction of EGR in the engine would reduce its efficiency upon increasing the levels, because the rate of EGR is rising and it impedes the normal cycle of combustion and reduces the efficiency of combustion as the volume of fresh oxygen required for combustion is substituted by flue gas in the cylinder which contributes to inadequate combustion of fuel and attenuates its performance. Rao [37] proved a similar trend of BTE with Cottonseed biodiesel.

Figure 5(b) shows the interactive impact of EGR rates and FIP on the BTE when the hold values (blend ratio and the load) are constant $(6.1 \%$ and $9.3 \mathrm{~kg})$. The surface plot of the response shows that for FIP to rise, the BTE should rise with all tested fuels. This is mainly owing to the greater degree of atomization at greater FIPs. Full combustion can also be assured even if the volume of injected fuel is the same at varying FIP. The response surface plot in Figure 5(c) explores the impact of blend ratio and FIP on BTE when hold values (EGR rates, load) are constant $(4.7 \%$ and 9.3 $\mathrm{kg})$. Figure 5(d) illustrates the combined effect of engine load and blend ratio on BTE when hold values (FIP, EGR) are constant. The surface plot of the response indicates that as the load increases on the 


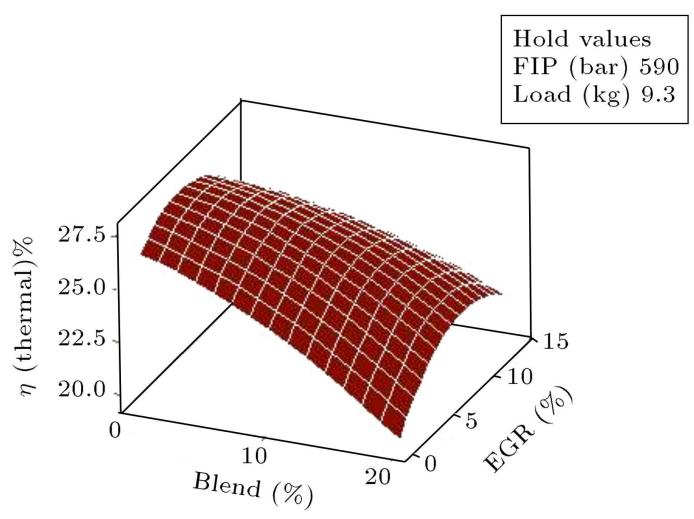

(a)

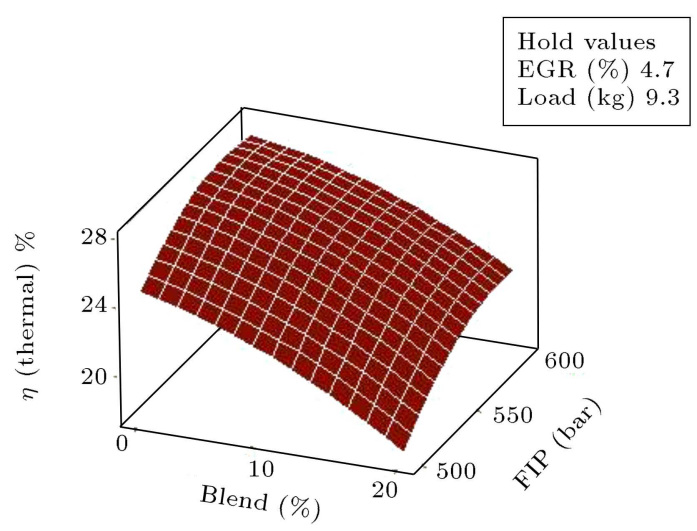

(c)

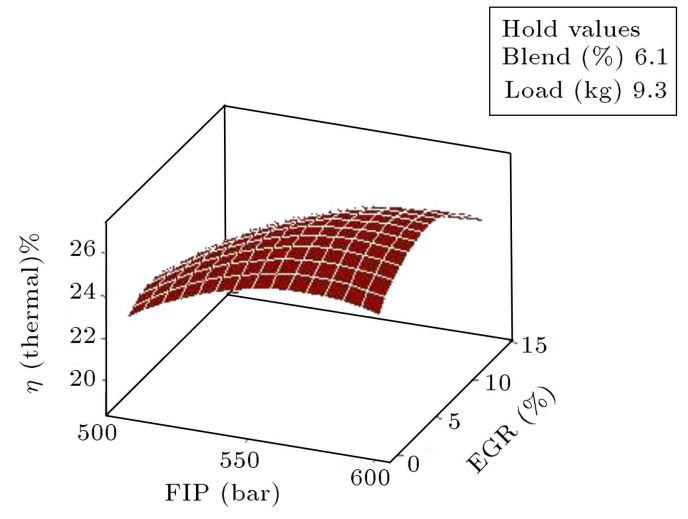

(b)

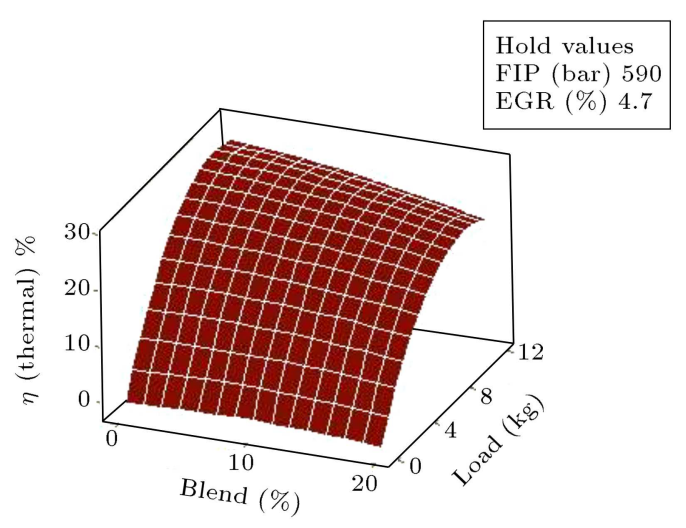

(d)

Figure 5. The effect of various engine input factors on brake thermal efficiency.

engine, its efficiency also increases, mainly because an increase in the torque and a reduction in $\mathrm{BSFC}$ with loads cause a rise in BTE.

\subsection{Impact of control factors on mechanical efficiency $\eta$ (Mech.)}

Figure 6(a) shows the combined effect of the blend ratio of linseed-diesel and EGR\% on mechanical efficiency while holding the values of FIP and the engine load. The ratio of Brake Power (BP) and IP indicates that power is known as mechanical efficiency. A similar trend was shown by castor biodiesel investigated by Md. Saiful Islam et al. [38]. It was found that $\eta$ (Mech.) would decrease with a rise in linseed in the blend because the low CV of linseed biodiesel correspondingly resulted in poor mechanical performance. As EGR rates increased, the corresponding value of mechanical efficiency decreased, mainly because EGR could promote improper combustion of fuel due to the replacement of fresh oxygen with flue gases inside the cylinder.

Figure 6(b) shows the interactive effect of EGR rates and FIP on the mechanical efficiency while holding the value of blend ratio and load at $(6.1 \%$ and $9.3 \mathrm{~kg})$. It was observed that mechanical efficiency was enhanced with an increase in FIP probably because of decreased viscosity, increased atomization, and better fuel combustion. The response surface plot in Figure 6(c) explores the impact of blend ratio and FIP on BTE on the mechanical efficiency when the hold values are (EGR rates, load) constant (4.7\% and 9.3 $\mathrm{kg})$. Figure 6(d) demonstrates the combined effect of engine load and blend ratio on mechanical efficiency when hold values (FIP, EGR) are constant. According to the findings, as the load increases, the corresponding value of mechanical efficiency increases, mainly due to increments in BP.

\subsection{Impact of control factors on Brake Mean Effective Pressure (BMEP)}

Figure 7 shows the response surface plot of BMEP with all input factors. Figure 7 (a) shows the combined effect of blend\% and EGR on BMEP when the hold values (FIP, load) are constant (590 bar and $9.3 \mathrm{~kg}$ ). The $\mathrm{BMEP}$ is the cumulative pressure of an engine cylinder on the piston head over a period which determines the engine ability to do the work. Slight differences in BMEP were observed for blend material. Such differences result from a decrease in BP with the blend as well as the BMEP. With a rise in EGR rates, the 


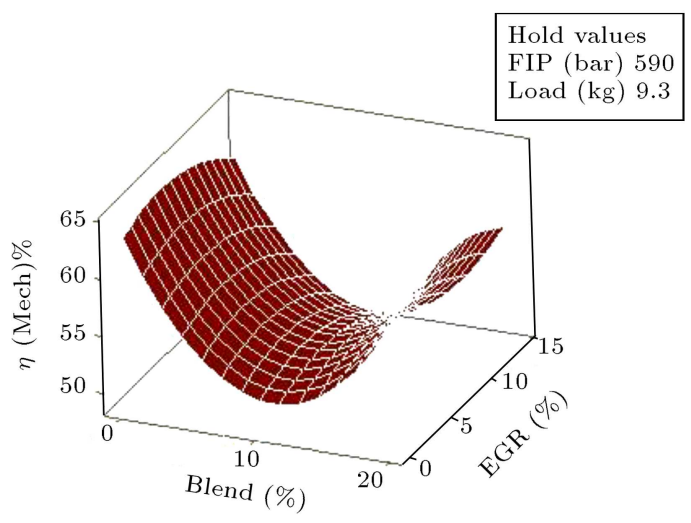

(a)

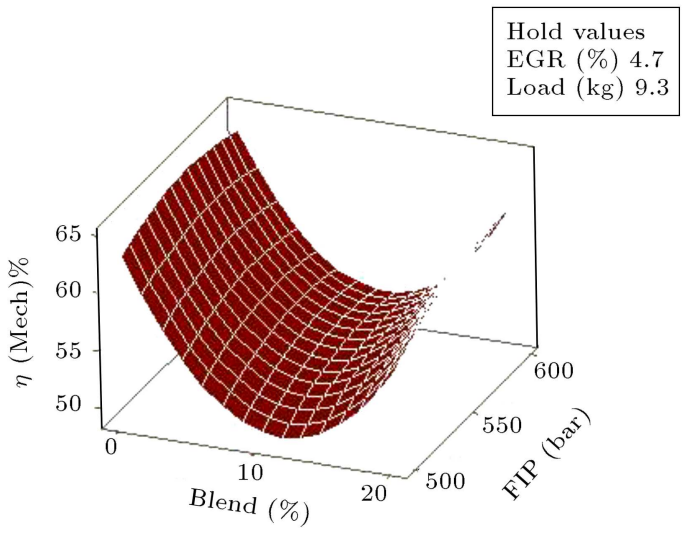

(c)

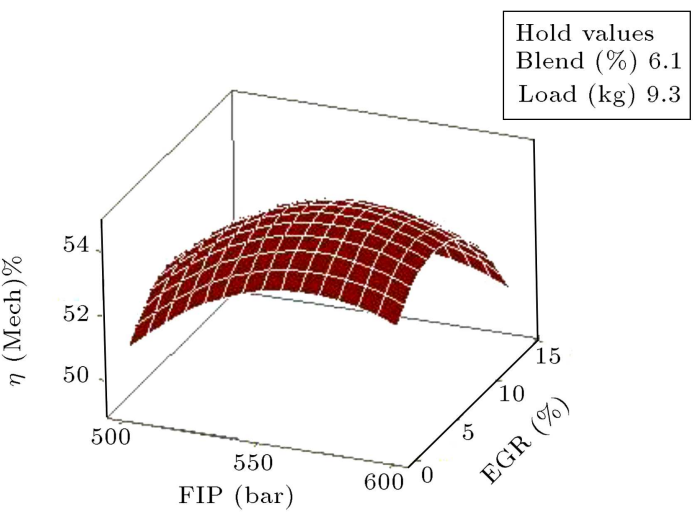

(b)

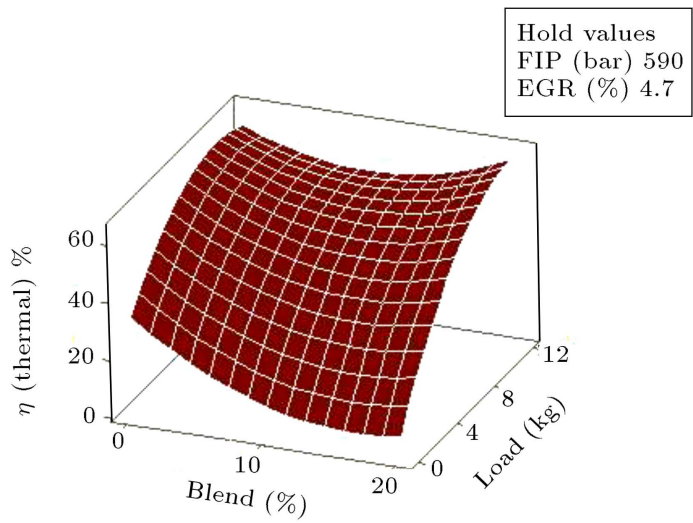

(d)

Figure 6. The effect of various engine input factors on mechanical efficiency.

BMEP was reduced due to the improper burning of fuel inside the cylinder.

Figure 7(b) shows the interactive impacts of input variable EGR rates and FIP on BMEP while holding the value of blend ratio and engine load. According to the findings, BMEP increased with an increase in FIP, probably because upon increasing FIP, better atomization of fuel inside the cylinder could be achieved which would, in turn, provide greater surface closure to ensure the complete combustion of fuel. Ge et al. [39] pointed to a similar trend in the CRDI engine when powered with canola biodiesel. The combined impacts of the blend content and FIP on BMEP are shown in Figure $7(\mathrm{c})$ when hold values are constant at $4.7 \%$ and 590 bar for EGR level and FIP, respectively. Figure 7(d) demonstrates the effect of load and blend\% on BMEP. According to the surface plot of response, as the load on engines increases, the corresponding BMEP also increases due to an increase in BP with the load.

\subsection{Impact of control factors on the torque}

The combined effects of linseed biodiesel in the blend, EGR rates, FIP, and engine loads on the torque are shown in Figure 8. The surface plots in Figure 8(a) indicate the impact of blend concentration and EGR rates on torque when the hold values (FIP, load) are constant (590 bar and $9.3 \mathrm{~kg}$ ). The quantity of torque was calculated by the amount of fuels supplied to the cylinders. As observed, engine torque decreased by increasing the volume of linseed biodiesel in the blend. This may result from higher viscosity and the density of biodiesel blend fuel as a similar trend was illustrated by de Carnival et al. [40] in a 54 kW mechanical fuel injection diesel engine. Since the heating value of biodiesel was smaller than that of the neat diesel, higher torque and smaller power generation was achieved due to the steadiness of the engine speed. Upon increasing the EGR rates, the corresponding value of torque decreased due to improper burning of fuel inside the cylinder.

The interactive effects of EGR rate and FIP on the torque are shown in Figure 8(b) while keeping the values of blend ratio and load at $6.1 \%$ and $9.3 \mathrm{~kg}$, respectively. The surface plot reveals that for all the test fuels, engine torque rises with FIP, mainly because with an increase in the FIP, a higher degree of atomization of the fuel droplets could be obtained, thus creating a more surface area for combustion. In addition, proper 


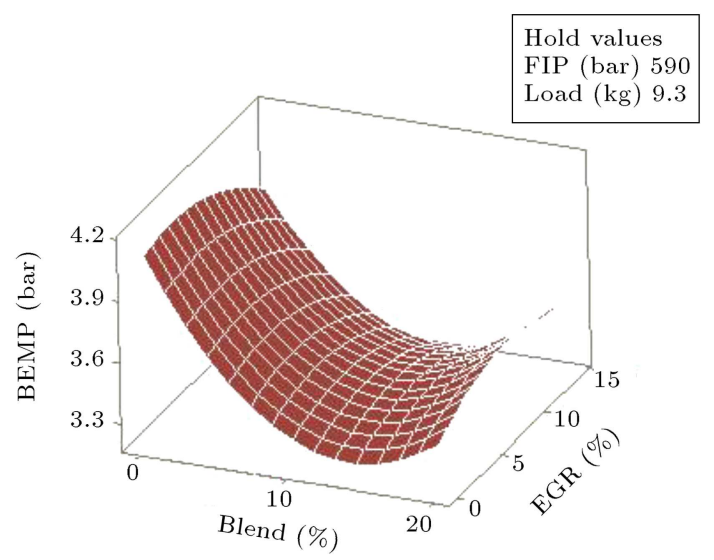

(a)

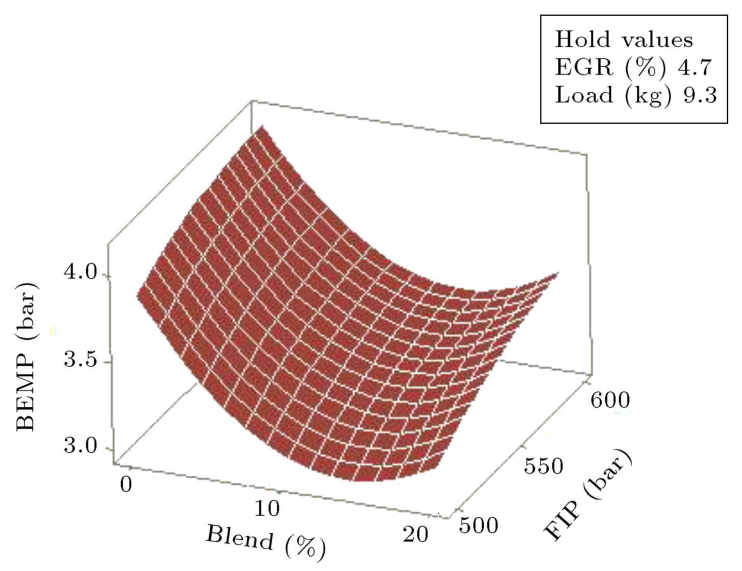

(c)

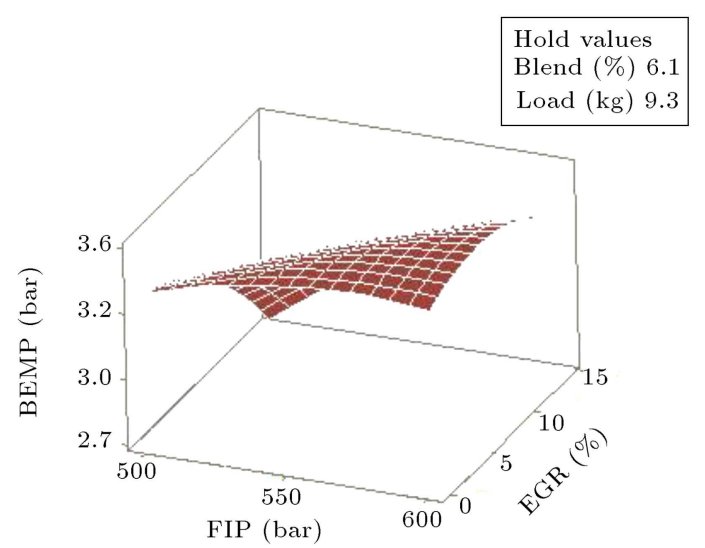

(b)

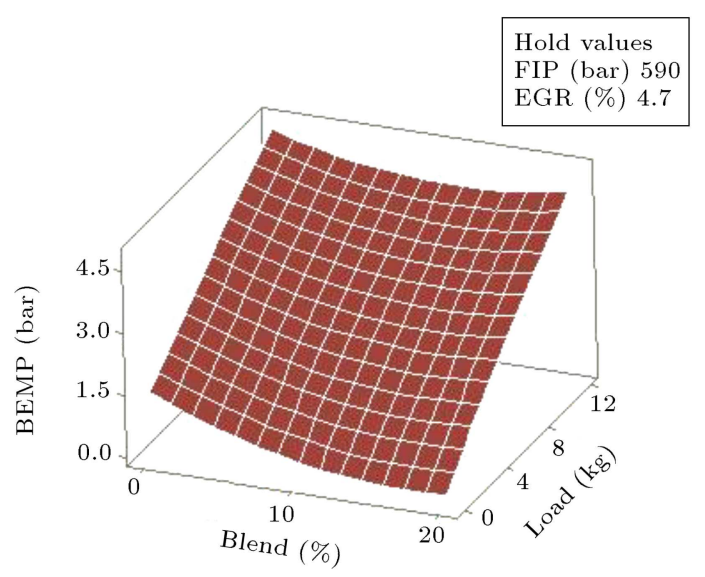

(d)

Figure 7. The effect of various engine input factors on brake effective mean pressure.

fuel combustion takes place, generating high torques on the engine. Figure 8(c) shows the effect of torque with blend content and FIP when hold values are constant at $(4.7 \%$ and $9.3 \mathrm{~kg})$ for EGR rates and engine load. The combined effects of load and blend content on torque are shown in Figure 8(d) while holding the value of FIP and EGR rates. It was observed that when the load on the engine increased, the corresponding values of torque would consequently increase. A load is an external force that is applied to the engine based on the type of dynamometer used. Since the load on the engine increases, the speed of the engine must be constant at $1500 \mathrm{rpm}$, which results in an increase in the torque to stabilize the speed of the engine.

\subsection{Impact of control factors on $\mathrm{HC}$ emission}

This section discusses the combined impact of all the input factors including blend ratio, FIP, EGR rates, and load on the emission of $\mathrm{HC}$, as illustrated in Figure 9. The effects of blend ratio and EGR rates are shown through the surface plot in Figure 9(a) while holding the value of FIP and load. The emission of $\mathrm{HC}$ was slightly reduced when the ratio of the blend increased. Less $\mathrm{HC}$ emission resulted from an increase in the blending volume, thus leading to a higher level of oxygen than diesel which, in turn, causes complete fuel combustion. HC emissions increase with higher levels of EGR, because the introduction of EGR in an engine allows for some flue gases flowing inside the combustion chamber instead of fresh oxygen, which causes poor fuel combustion.

Figure $9(\mathrm{~b})$ shows the FIP and EGR response surface plot for $\mathrm{HC}$ emissions. According to Figure 9(b), as the FIP raises, $\mathrm{HC}$ decreases due to optimized oxygen consumption, contributing to stronger fuel combustion. Channapattana et al. [41] detected a similar trend of $\mathrm{HC}$ for Honne biodiesel. The interactive effects of blend ratio and FIP on HC emission whose response surface plot is shown in Figure 9(c) when hold values (EGR rates, load) are constant (4.7\% and $9.3 \mathrm{~kg})$. The combined effect of load and blend ratio is shown in Figure $9(\mathrm{~d})$ by holding the value of FIP and the EGR rates. It was found that as the load on 


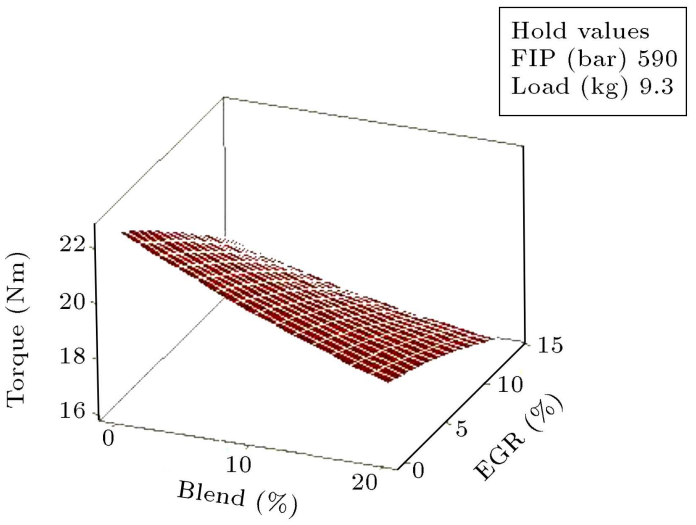

(a)

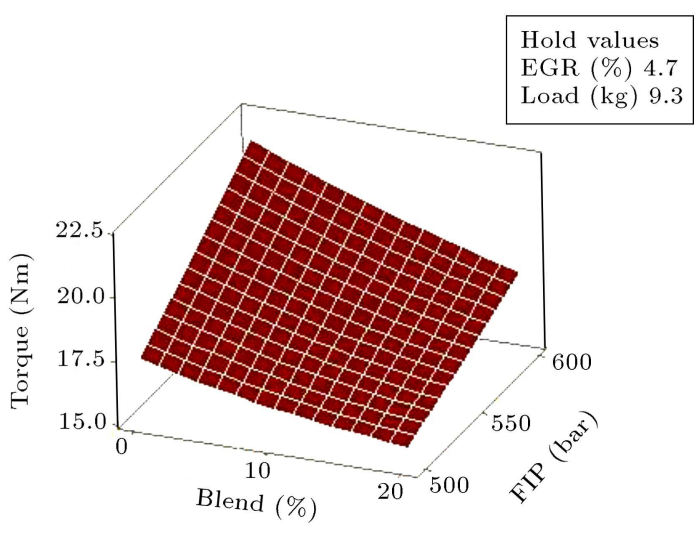

(c)

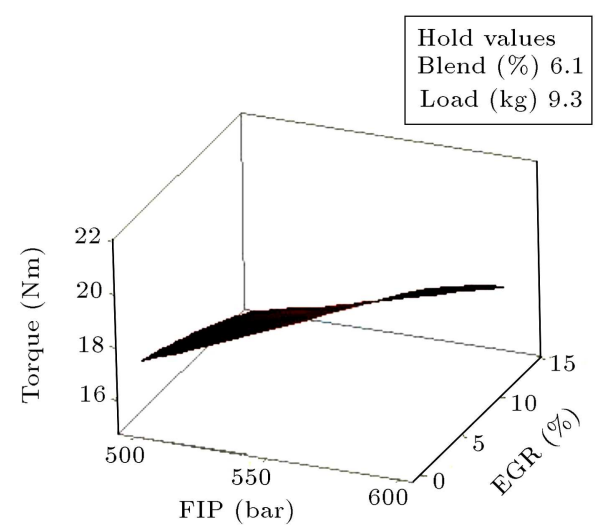

(b)

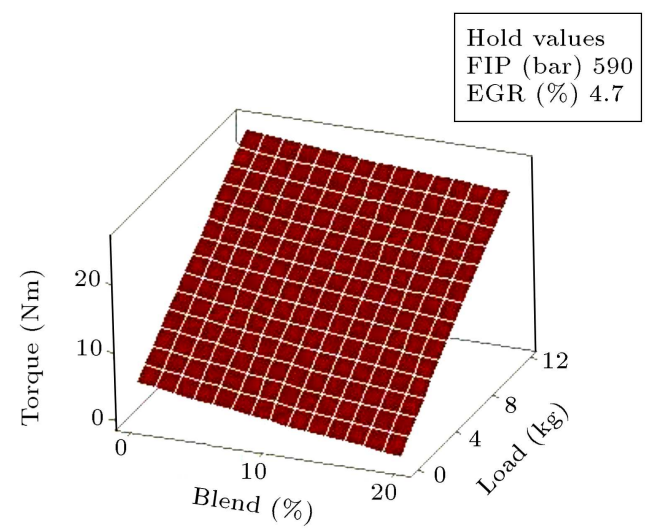

(d)

Figure 8. The effect of various engine input factors on torque.

the engine increases, the corresponding $\mathrm{HC}$ emission reduces. This phenomenon occurs due to the addition of a rich mixture of air and fuel inside the combustion chamber owing to the higher fuel consumption resulting in premature combustion which contributes to higher $\mathrm{HC}$ emissions.

\subsection{Impact of control factors on the emission of $\mathrm{CO}_{2}$}

From the response surface plot, the impacts of various input parameters such as blend ratio, FIP, EGR levels, and engine load on $\mathrm{CO}_{2}$ emissions are shown in Figure 10. It is advantageous to maximize $\mathrm{CO}_{2}$ emission as it is implied that the fuel combustion in the cylinder takes place properly and the $\mathrm{CO}$ molecules are converted into $\mathrm{CO}_{2}$ gas due to the availability of fresh oxygen. The surface plot in Figure 10(a) shows the effect of $\mathrm{CO}_{2}$ with blend ratio and EGR rate when the hold values (FIP, the engine load) are constant (590 bar and $9.33 \mathrm{~kg}$ ). It was reported that as the quantity of linseed biodiesel in the blend increased, the $\mathrm{CO}_{2}$ emissions reduced substantially. Carbon dioxide is produced when the fuel is completely combusted in oxygen. Herein, $\mathrm{CO}_{2}$ formation is small since biodiesel is typically a low-carbon product and has a lower ratio of elemental carbon and hydrogen relative to diesel fuel. EGR reduces $\mathrm{CO}_{2}$ emissions as the exhaust gas injected rather than fresh air results in incomplete burning in the combustion chamber. Thus, insufficient oxygen supply does not convert $\mathrm{CO}$ into $\mathrm{CO}_{2}$ and reduces $\mathrm{CO}_{2}$ emissions. Kanthasamy et al. [42] found a similar trend on CRDI engine powered with tallow methyl ester biodiesel blends.

Figure 10(b) shows the interactive impact of EGR rates and FIP on the emission of $\mathrm{CO}_{2}$ when the hold values (blend ratio, the load) are constant $(6.1 \%$ and $9.3 \mathrm{~kg})$. It was found that with the increase in FIP, the $\mathrm{CO}_{2}$ emission increased. This was probably due to the fact that in case of higher FIP, the fuel would be easily atomized, thus promoting proper combustion of fuel and $\mathrm{CO}$ being converted into $\mathrm{CO}_{2}$. Thus, the level of $\mathrm{CO}_{2}$ increases. The response surface plot in Figure 10(c) explores the impact of blend ratio and FIP on $\mathrm{CO}_{2}$ emission when hold values (EGR rates, load) are constant $(4.7 \%$ and $9.3 \mathrm{~kg})$. Figure $10(\mathrm{~d})$ shows the combined effect of engine load and blend ratio on $\mathrm{CO}_{2}$ emission when hold values (FIP and EGR level) are constant. It has been found that the $\mathrm{CO}_{2}$ emission 


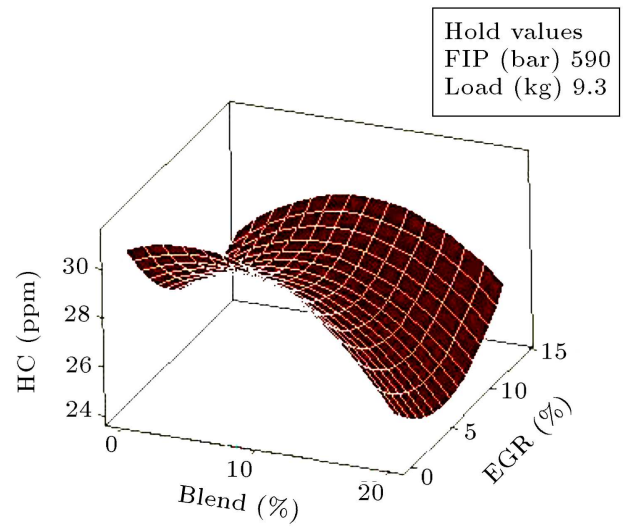

(a)

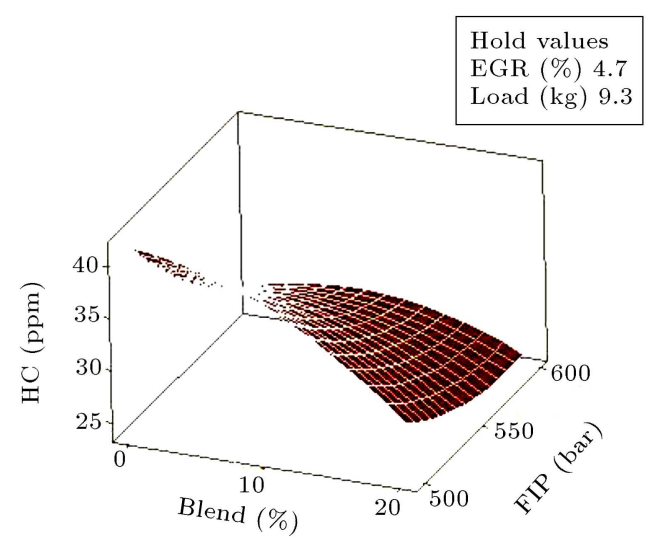

(c)

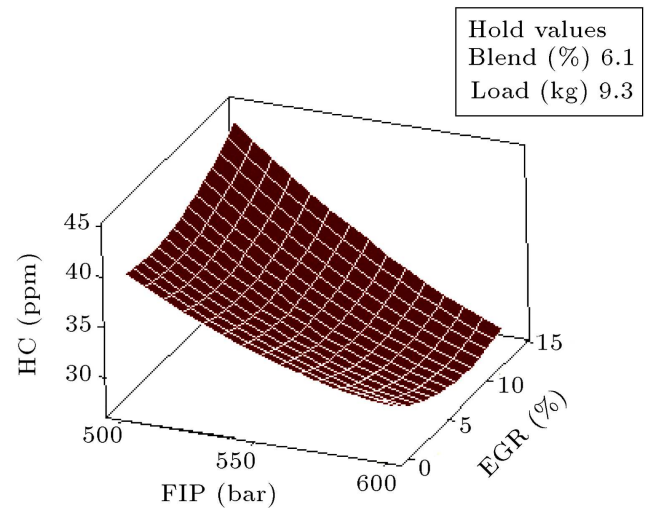

(b)

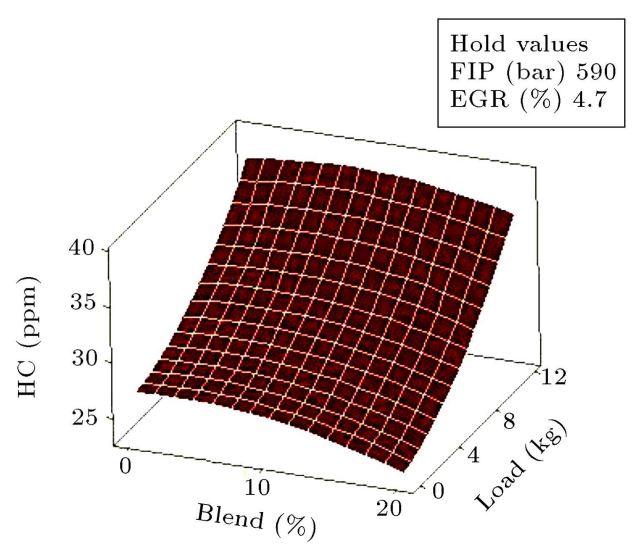

(d)

Figure 9. The effect of various engine input factors on the emission of HC (Hydrocarbon).

Table 10. The experimental values with their mean and standard deviation of various engine output parameters.

\begin{tabular}{cccccc}
\hline $\begin{array}{c}\text { Output } \\
\text { parameters }\end{array}$ & \multicolumn{3}{c}{$\begin{array}{c}\text { Experimental outcomes } \\
\text { (no. of trials) }\end{array}$} & $\begin{array}{c}\text { Mean } \\
\text { value }\end{array}$ & $\begin{array}{c}\text { Standard } \\
\text { deviation }\end{array}$ \\
\hline BTE (\%) & 25.23 & 24.66 & 25.62 & 25.17 & 0.4662 \\
BMEP (bar) & 3.382 & 3.415 & 3.379 & 3.392 & 0.0008 \\
Torque (Nm) & 19.91 & 19.16 & 19.76 & 19.61 & 0.315 \\
$\eta$ (Mech) & 50.78 & 48.94 & 51.06 & 50.26 & 2.65 \\
$\mathrm{HC}$ (ppmv) & 30 & 30 & 30 & 30 & 0 \\
$\mathrm{CO}_{2}$ (\%vol) & 7.549 & 7.921 & 7.621 & 7.697 & 0.0777 \\
\hline
\end{tabular}

rises with increased load due to improved combustion and more fuel burns at high loads.

\subsection{Experimental tests and validations}

The need for optimization is to enhance the performance of engine BTE, BMEP, torque, and mechanical efficiency with $\mathrm{CO}_{2}$ and minimize the emission of HC. The desirability value obtained is 0.8032 and is recommended for use since it almost meets the optimization criteria. This measure needs the validation and evaluation of the optimized output. To do this, the experimental test was performed for the configuration of the obtained input variables using RSM techniques and the test was repeated 3 times. From the outcomes, their mean value and the standard deviation were calculated and mentioned in Table 10.

The mean values for the outcomes of these experimental tests were correlated with the predicted values for RSM model and the error was estimated, as seen in Table 11. It was found that there was a slight difference between the experimental results and the predicted value of the output variables. The error $\%$ age for BTE, 


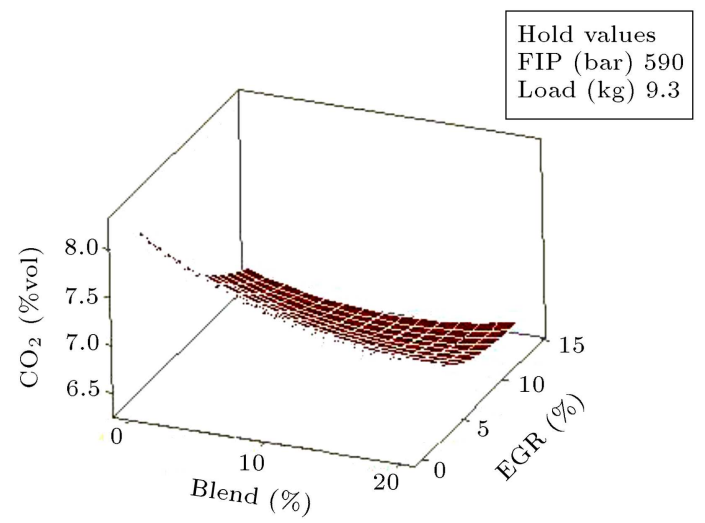

(a)

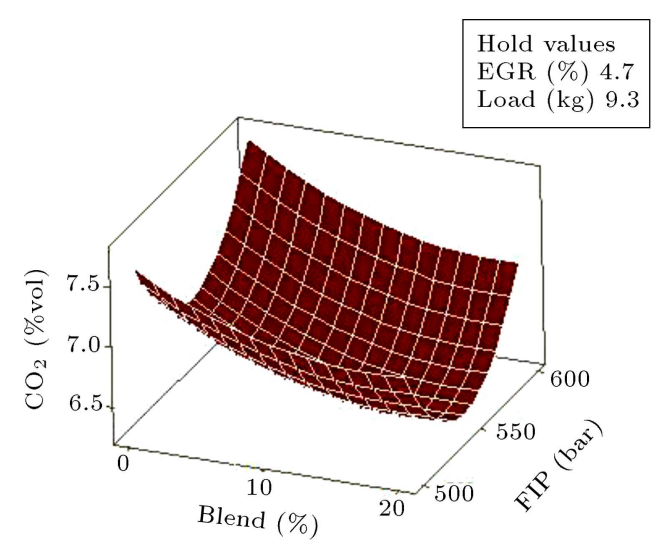

(c)

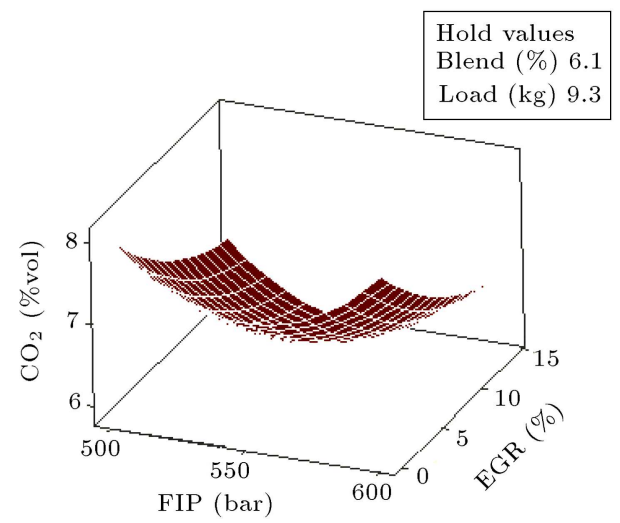

(b)

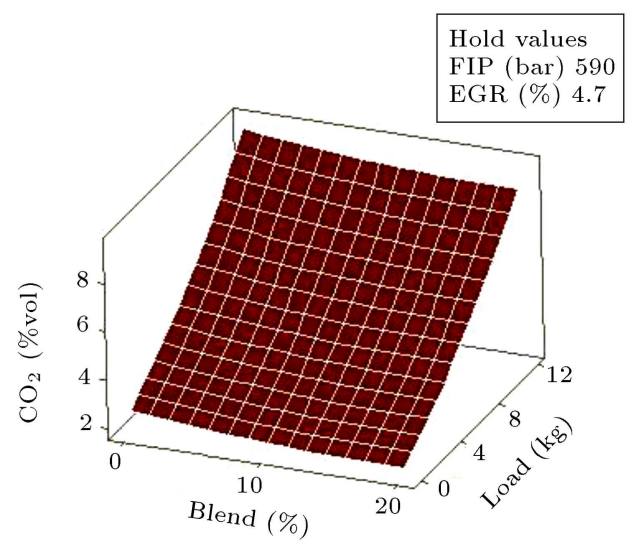

(d)

Figure 10. The effect of various engine input factors on $\mathrm{CO}_{2}$ emission.

Table 11. Validation of output variables.

\begin{tabular}{ccccccc}
\hline $\begin{array}{c}\text { Engine } \\
\text { outcomes }\end{array}$ & $\begin{array}{c}\text { BTE } \\
(\boldsymbol{\%})\end{array}$ & $\begin{array}{c}\text { BMEP } \\
(\mathbf{b a r})\end{array}$ & $\begin{array}{c}\text { Torque } \\
(\mathbf{N m})\end{array}$ & $\begin{array}{c}\boldsymbol{\eta} \\
(\mathbf{M e c h})\end{array}$ & $\begin{array}{c}\mathbf{H C} \\
(\mathbf{p p m v})\end{array}$ & $\begin{array}{c}\mathbf{C O}_{2} \\
(\boldsymbol{\%} \text { vol) }\end{array}$ \\
\cline { 2 - 7 } & $\mathbf{1}$ & $\mathbf{2}$ & $\mathbf{3}$ & $\mathbf{4}$ & $\mathbf{5}$ & $\mathbf{6}$ \\
\hline Predicted value (RSM) & 26.035 & 3.474 & 20.04 & 52.503 & 28.14 & 7.319 \\
Experimental value & 25.17 & 3.392 & 19.61 & 50.26 & 30 & 7.697 \\
Error (\%) & 3.32 & 2.36 & 2.14 & 4.27 & 6.60 & 5.1 \\
\hline
\end{tabular}

BMEP, torque, mechanical efficiency, $\mathrm{HC}$, and $\mathrm{CO}_{2}$ was $3.32 \%, 2.36 \%, 2.14 \%, 4.27 \%, 6.60 \%$, and $5.175 \%$, contained in a limited range. The graph shown in Figure 11 indicates the difference between the predicted value and experimental value engine outcomes values as the values of the engine outcome.

\section{Conclusions}

The performance and pollutant parameters of a fourstroke Common Rail Direct Injection (CRDI) diesel engine powered by linseed biodiesel/diesel blends were analyzed in this study. The innovation of this research lies in its optimization of the operating factors of the engine operated by DOE (Design Of Experiment)/RSM (Response Surface Methodology) run with linseed biodiesel and diesel blends. A range of linseed biodiesel ratios $(5 \%, 10 \%, 15 \%$, and $20 \%)$, engine loads (0 kg, $3 \mathrm{~kg}, 6 \mathrm{~kg}, 9 \mathrm{~kg}$, and $12 \mathrm{~kg}$ ), Exhaust Gas Recirculation (EGR) rates $(0 \%, 3.5 \%, 7 \%, 10.5 \%$, and 14\%), and Fuel Injection Pressures (FIP) (500 $\mathrm{kPa}, 525 \mathrm{kPa}, 550 \mathrm{kPa}, 575 \mathrm{kPa}$, and $600 \mathrm{kPa}$ ) were selected as input parameters for this analysis. To evaluate the optimal engine operating conditions to achieve enhanced efficiency and emission parameters, the RSM approach was employed. The following conclusions can be drawn based on the findings of this study. 


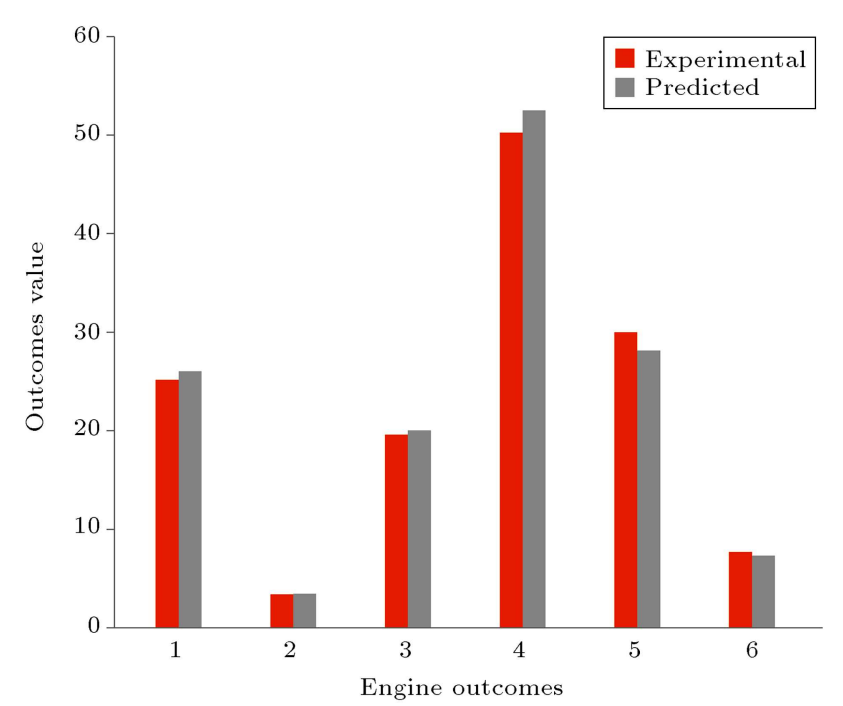

Figure 11. The difference between the predicted values and experimental values of engine outcomes (see Table 11).

1. The software-designed experiments helped determine the exact responses;

2. The best desirability of 0.8032 was achieved using the desirability method of RSM;

3. It was revealed that 600 bar FIP, $4.667 \%$ EGR, and $9.33 \mathrm{~kg}$ engine load as well as the $8.10 \%$ linseed/diesel blend ratio were best fit for achieving the optimum output and emissions from the CRDI engine. In addition, with these optimal configurations of FIP, EGR, linseed blend, and engine load, the measured output parameters included a Brake Thermal Efficiency (BTE) of $25.17 \%$, Brake Mean Effective Pressure (BMEP) of 3.392 bar, torque of $19.61 \mathrm{Nm}, \eta$ (Mech.) of $50.26 \%$, HC of $30 \mathrm{ppmv}$, and $\mathrm{CO}_{2}$ of $7.697 \%$ vol, all relatively close to experimental values, i.e., 26.035\%, 3.474 bar, $20.04 \mathrm{Nm}$, $52.503 \%, 28.14$ ppmv, for BTE, BMEP, torque, $\eta$ (Mech), $\mathrm{HC}$, and $\mathrm{CO}_{2}$, respectively, measured with the optimized combination of input variables;

4. As observed, BTE and BMEP decreased with an increment in linseed quantity in the blend;

5. The values of $R^{2}$ (correlation coefficient) for torque, BTE, mechanical efficiency, BMEP, $\mathrm{HC}$, and $\mathrm{CO}_{2}$ were $99.57 \%, 80.85 \%, 84.97 \%, 96.54 \%, 88.57 \%$, and $96.58 \%$, respectively;

6. It was also found that with an increase in FIP, HC and $\mathrm{CO}_{2}$ emissions would decrease and increase, respectively. An increment in $\mathrm{CO}_{2}$ was desirable because it proved that the combustion of fuel took place properly and most of the $\mathrm{CO}$ molecules were converted into $\mathrm{CO}_{2}$.

Therefore, it can be concluded that RSM is an important tool for multi-objective engine optimization. By arranging the blend ratio, FIP, EGR rates, and engine load while using a linseed biodiesel blend, superior efficiency and controlled emission characteristics were achieved. In order to discover the ideal factor ratios for the CRDI diesel engine powered by linseed biodiesel blends, RSM and desirability approach were effectively used.

\section{Acknowledgments}

The author would be grateful to the faculty members of the Mechanical Engineering Department, Delhi Technological University, Delhi, India to make this experiment useful by giving the required equipment and machine.

\section{Nomenclature}

$\begin{array}{ll}\text { ASTM } & \text { American Standard Test Method } \\ \text { ANOVA } & \text { Analysis of Variance } \\ \text { BMEP } & \text { Brake Mean Effective Pressure } \\ \text { BP } & \text { Brake Power } \\ \text { bTDC } & \text { Before Top Dead Centre } \\ \text { BTE } & \text { Brake Thermal Efficiency } \\ \text { CI } & \text { Compression Ignition } \\ \text { CO } 2 & \text { Carbon dioxide } \\ \text { CN } & \text { Cetane Number } \\ \text { CV } & \text { Calorific Value } \\ \text { CRDI } & \text { Common Rail Direct Injection } \\ \text { DOE } & \text { Design Of Experiment } \\ \text { F/A ratio } & \text { Fuel Air ratio } \\ \text { FIP } & \text { Fuel Injection Pressure } \\ \text { HC } & \text { Hydrocarbon } \\ \text { LB5 } & \text { Diesel 95\% + Linseed Biodiesel } 5 \% \\ \text { LB10 } & \text { Diesel 90\% + Linseed Biodiesel 10\% } \\ \text { LB15 } & \text { Diesel 85\% + Linseed Biodiesel 15\% } \\ \text { LB20 } & \text { Diesel 80\% + Linseed Biodiesel 20\% } \\ \text { KOH } & \text { Potassium hydroxide } \\ \text { NOx } & \text { Oxides of nitrogen } \\ \text { NaOH } & \text { Sodium hydroxide } \\ \eta(M e c h) & \text { Mechanical efficiency } \\ \text { PM } & \text { Particulate Matters } \\ \text { RCCD } & \text { Rotable Central Composite Design }\end{array}$

\section{References}

1. Singh, V., Agarwal, T., Saroha, N., et al. "Performance emissions and combustion analysis of CI engine using ethyl ester kusum oil and butanol blends" (No. 201901-0568), SAE Technical Paper (2019).

2. Gautam, R. and Kumar, N. "Performance emission and combustion studies of diesel engine on Jatropha 
ethyl ester and its higher alcohol blends", International Journal of Global Warming, 14(2), pp. 159-169 (2018).

3. Saravanan, A., Murugan, M., Reddy, M.S., et al. "Performance and emission characteristics of variable compression ratio CI engine fueled with dual biodiesel blends of Rapeseed and Mahua", Fuel, 263(1), pp. 116751 (2020).

4. Karikalan, L., Jacob, S., Baskar, S., et al. "Analyzing the influence of varied fuel injection pressure on diesel engine fueled with Karanja biodiesel", Materials Today: Proceedings, 21(1), pp. 291-294 (2020).

5. Rajesh Kumar, B. and Saravanan, S. "Use of higher alcohol biofuels in diesel engines: A review", Renewable and Sustainable Energy Reviews, 60, pp. 84-115 (2016).

6. Gautam, R., Ansari, N., Sharma, A., and Singh, Y. "Development of the ethyl ester from Jatropha oil through response surface methodology approach", Pollution, 6(1), pp. 135-147 (2020).

7. Yongphet, P., Wang, J., Wang, D., et al. "Optimization of operation conditions for biodiesel preparation from soybean oil using an electric field", Biomass Conversion and Biorefinery, 11(5), pp. 2041-2051 (2021).

8. Dixit, S. and Rehman, A. "Linseed oil as a potential resource for bio-diesel: a review", Renewable and Sustainable Energy Reviews, 16(7), pp. 4415-4421 (2012).

9. Ansari, N.A., Sharma, A., and Singh, Y. "Performance and emission analysis of a diesel engine implementing polanga biodiesel and optimization using Taguchi method", Process Safety and Environmental Protection, 120, pp. 146-154 (2018).

10. Venu, H., Subramani, L., and Raju, V.D. "Emission reduction in a DI diesel engine using exhaust gas recirculation (EGR) of palm biodiesel blended with $\mathrm{TiO}_{2}$ nano additives", Renewable Energy, 140, pp. 245-263 (2019).

11. Kannan, G.R. and Anand, R. "Effect of injection pressure and injection timing on DI diesel engine fuelled with biodiesel from waste cooking oil", Biomass and Bioenergy, 46, pp. 343-352 (2012).

12. Agarwal, A.K., Dhar, A., Gupta, J.G., et al. "Effect of fuel injection pressure and injection timing of Karanja biodiesel blends on fuel spray, engine performance, emissions and combustion characteristics", Energy Conversion and Management, 91, pp. 302-314 (2015).

13. Tosun, E., Aydin, K., and Bilgili, M. "Comparison of linear regression and artificial neural network model of a diesel engine fueled with biodiesel-alcohol mixtures", Alexandria Engineering Journal, 55(4), pp. 3081-3089 (2016).

14. Pathak, A., Choudhury, P.K., and Dutta, R.K. "Taguchi-grey relational based multi-objective optimization of process parameters on the emission and fuel consumption characteristics of A VCR petrol engine", Materials Today: Proceedings, 5(2), pp. 47024710 (2018).
15. Ghasemi, H., Park, H.S., and Rabczuk, T. "A level-set based IGA formulation for topology optimization of flexoelectric materials", Computer Methods in Applied Mechanics and Engineering, 313, pp. 239-258 (2017).

16. Hamze, H., Akia, M., and Yazdani, F. "Optimization of biodiesel production from the waste cooking oil using response surface methodology", Process Safety and Environmental Protection, 94, pp. 1-10 (2015).

17. Ma, L., Han, Y., Sun, K., Lu, J., and Ding, J. "Optimization of acidified oil esterification catalyzed by sulfonated cation exchange resin using response surface methodology", Energy Conversion and Management, 98, pp. 46-53 (2015).

18. Vinay, Singh, B., and Yadav, A.K. "Optimisation of performance and emission characteristics of CI engine fuelled with Mahua oil methyl ester-diesel blend using response surface methodology", International Journal of Ambient Energy, 41(6), pp. 674-685 (2020).

19. Uslu, S. and Celik, M.B. "Performance and exhaust emission prediction of a SI engine fueled with I-amyl alcohol-gasoline blends: An ANN coupled RSM based optimization", Fuel, 265, p. 116922 (2020).

20. Esonye, C., Onukwuli, O.D., and Ofoefule, A.U. "Optimization of methyl ester production from Prunus Amygdalus seed oil using response surface methodology and artificial neural networks", Renewable energy, 130, pp. 61-72 (2019).

21. Molina, S., Guardiola, C., Martín, J., et al. "Development of a control-oriented model to optimise fuel consumption and NOX emissions in a DI Diesel engine", Applied Energy, 119, pp. 405-416 (2014).

22. Krishnamoorthi, M., Malayalamurthi, R., and Shameer, P.M. "RSM based optimization of performance and emission characteristics of DI compression ignition engine fuelled with diesel/aegle marmelos oil/diethyl ether blends at varying compression ratio, injection pressure and injection timing", Fuel, 221, pp. 283-297 (2018).

23. Yatish, K.V., Lalithamba, H.S., Suresh, R., et al. "Optimization of bauhinia variegata biodiesel production and its performance, combustion and emission study on diesel engines", Renewable Energy, 122, pp. 561575 (2018).

24. Najafi, B., Faizollahzadeh Ardabili, S., Mosavi, A., et al. "An intelligent artificial neural network-response surface methodology method for accessing the optimum biodiesel and diesel fuel blending conditions in a diesel engine from the viewpoint of exergy and energy analysis", Energies, 11(4), p. 860 (2018).

25. Parida, M.K., Joardar, H., Rout, A.K., et al. "Multiple response optimizations to improve performance and reduce emissions of Argemone Mexicana biodieseldiesel blends in a VCR engine", Applied Thermal Engineering, 148, pp. 1454-1466 (2019).

26. Singh, Y., Sharma, A., Singh, G.K., et al. "Optimization of performance and emission parameters of direct injection diesel engine fuelled with pongamia methyl 
esters-response surface methodology approach", Industrial Crops and Products, 126, pp. 218-226 (2018).

27. Sakthivel, R., Ramesh, K., Marshal, S.J.J., et al. "Prediction of performance and emission characteristics of diesel engine fuelled with waste biomass pyrolysis oil using response surface methodology", Renewable Energy, 136, pp. 91-103 (2019).

28. Veinblat, M., Baibikov, V., Katoshevski, D., et al. "Impact of various blends of linseed oil-derived biodiesel on combustion and particle emissions of a compression ignition engine-A comparison with diesel and soybean fuels", Energy Conversion and Management, 178, pp. 178-189 (2018).

29. Agarwal, A.K. "Experimental investigations of the effect of biodiesel utilization on lubricating oil tribology in diesel engines", Proceedings of the Institution of Mechanical Engineers, Part D., Journal of Automobile Engineering, 219(5), pp. 703-713 (2005).

30. Experiment Engine Set Up, Automobile Lab (24/02/2020) of Delhi Technological University, Delhi (2020).

31. Saravanan, S. "Effect of exhaust gas recirculation (EGR) on performance and emissions of a constant speed DI diesel engine fueled with pentanol/diesel blends", Fuel, 160, pp. 217-226 (2015).

32. Samaniego, E., Anitescu, C., Goswami, S., et al. "An energy approach to the solution of partial differential equations in computational mechanics via machine learning: Concepts, implementation and applications", Computer Methods in Applied Mechanics and Engineering, 362, p. 112790 (2020).

33. Vu-Bac N., Lahmer, T., Zhuang, X., et al. "A software framework for probabilistic sensitivity analysis for computationally expensive models", Advances in Engineering Software, 100, pp. 19-31 (2016).

34. Bauer, J.r., K.W., Parnell, G.S., and Meyers, D.A. "Response surface methodology as a sensitivity analysis tool in decision analysis", Journal of Multi-Criteria Decision Analysis, 8(3), pp. 162-180 (1999).

35. Awad, O.I., Mamat, R., Ali, O.M., et al. "Response surface methodology (RSM) based multi-objective optimization of fuel oil-gasoline blends at different water content in SI engine", Energy Conversion and Management, 150, pp. 222-241 (2017).

36. Saríkaya, M. and Güllü, A. "Taguchi design and response surface methodology based analysis of machining parameters in CNC turning under MQL", Journal of Cleaner Production, 65, pp. 604-616 (2014).

37. Rao, K.S. "Effect of EGR on diesel engine performance and exhaust emission running with cotton seed biodiesel", International Journal of Mechanical and Mechatronic Engineering, 16(02), pp. 64-69 (2016).
38. Islam, M., Ahmed, A.S., Islam, A., et al. "Study on emission and performance of diesel engine using castor biodiesel", Journal of Chemistry, 2014, Article ID 451526 (2014).

39. Ge, J.C., Yoon, S.K., Kim, M.S., et al. "Application of canola oil biodiesel/diesel blends in a common rail diesel engine", Applied Sciences, 7(1), p. 34 (2017).

40. de Carvalho, M.A., Achy, A.R., Junior, L.C., et al. "Mechanical and emissions performance of a diesel engine fueled with biodiesel, ethanol and diethyl ether blends", Journal of the Brazilian Society of Mechanical Sciences and Engineering, 42(4), pp. 1-10 (2020).

41. Channapattana, S.V., Pawar, A.A., and Kamble, P.G. "Optimisation of operating parameters of DICI engine fueled with second generation Bio-fuel and development of ANN based prediction model", Applied Energy, 187, pp. 84-95 (2017).

42. Kanthasamy, P., Selvan, V., Mozhi, A., et al. "Investigation on the performance, emissions and combustion characteristics of CRDI engine fueled with tallow methyl ester biodiesel blends with exhaust gas recirculation", Journal of Thermal Analysis and Calorimetry, 141(6), pp. 2325-2333 (2020).

\section{Biographies}

Manish Kumar is a Research Scholar (MTech). He has completed his MTech from Delhi Technological University (formally DCE), Delhi in Thermal Engineering and received BTech in Mechanical Engineering from Dev Bhoomi Institute of Technology, Dehradun. His research interests include renewable energy, bio fuels, IC engine, etc. He has a research paper in SCI journal and an international conference paper.

Naushad Ahmad Ansari is presently working as an Assistant Professor at the Department of Mechanical Engineering, Delhi Technological University, Delhi. He has more than 20 years of teaching experience. His specialization lies in thermal engineering. He has published various research articles in reputed international journals and also reviewed various articles for journals.

Abhishek Sharma has 17 years of international involvement in Academic Teaching \& Research across recognized Indian and African Universities. He has published over fifty research articles in SCI/SCIE \& SCOPUS indexed journals and other peer-reviewed journals, ISBN book, and IEEE conference proceedings. He serves as the reviewer and editorial board member of peer-reviewed journals and conferences.

Varun Kumar Singh is a Research Scholar (MTech). He completed his MTech from Delhi Technological University (formally DCE), Delhi in Thermal Engineering and received BTech in Mechanical Engineering 
from SCRIET (CCS University), Meerut. His research interests include renewable energy, biofuels, and IC engine. He has presented a research paper in SCI journal and one international conference paper.

Raghvendra Gautam is presently working as an Assistant Professor at the Department of Mechanical Engineering, Delhi Technological University, Delhi. He has more than 11 years of teaching experience. His specialization is Thermal Engineering. He has published various research articles in reputed inter- national journals and reviewed various articles of the journals.

Yashvir Singh is presently working as an Associate Professor at the Department of Mechanical Engineering, Graphic Era deemed to be University, Dehradun. He has more than 12 years of teaching experience. He specializes in tribology, biofuels, lubrication, manufacturing, etc. He has published various research papers in reputed journals and reviewed various paper articles in the journals. 